\title{
Applications of Unmanned Aerial Vehicles in Cryosphere: Latest Advances and Prospects
}

\author{
Clare Gaffey ${ }^{1, *}$ and Anshuman Bhardwaj ${ }^{2}$ (B) \\ 1 Graduate School of Geography, Clark University, Worcester, Massachusetts, MA 01610, USA \\ 2 Division of Space Technology, Department of Computer Science, Electrical and Space Engineering, \\ Luleå University of Technology, 97187 Luleå, Sweden; anshuman.bhardwaj@ltu.se \\ * Correspondence: cgaffey@clarku.edu; Tel.: +1-508-793-7336
}

Received: 18 February 2020; Accepted: 13 March 2020; Published: 15 March 2020

\begin{abstract}
Owing to usual logistic hardships related to field-based cryospheric research, remote sensing has played a significant role in understanding the frozen components of the Earth system. Conventional spaceborne or airborne remote sensing platforms have their own merits and limitations. Unmanned aerial vehicles (UAVs) have emerged as a viable and inexpensive option for studying the cryospheric components at unprecedented spatiotemporal resolutions. UAVs are adaptable to various cryospheric research needs in terms of providing flexibility with data acquisition windows, revisits, data/sensor types (multispectral, hyperspectral, microwave, thermal/night imaging, Light Detection and Ranging (LiDAR), and photogrammetric stereos), viewing angles, flying altitudes, and overlap dimensions. Thus, UAVs have the potential to act as a bridging remote sensing platform between spatially discrete in situ observations and spatially continuous but coarser and costlier spaceborne or conventional airborne remote sensing. In recent years, a number of studies using UAVs for cryospheric research have been published. However, a holistic review discussing the methodological advancements, hardware and software improvements, results, and future prospects of such cryospheric studies is completely missing. In the present scenario of rapidly changing global and regional climate, studying cryospheric changes using UAVs is bound to gain further momentum and future studies will benefit from a balanced review on this topic. Our review covers the most recent applications of UAVs within glaciology, snow, permafrost, and polar research to support the continued development of high-resolution investigations of cryosphere. We also analyze the UAV and sensor hardware, and data acquisition and processing software in terms of popularity for cryospheric applications and revisit the existing UAV flying regulations in cold regions of the world. The recent usage of UAVs outlined in 103 case studies provide expertise that future investigators should base decisions on.
\end{abstract}

Keywords: UAV; unmanned aerial systems (UAS); drone; cryosphere; arctic; polar; remote sensing

\section{Introduction}

"Cryosphere" refers to the frozen component of water in the form of glaciers, snow cover, ice sheets, ice caps, frozen lakes and rivers, sea ice, and frozen ground or permafrost. Owing to high albedo characteristics of snow and ice and their physical interactions with the other components of the Earth system, the cryosphere plays an important role in the global biogeochemical cycles and energy balance. This means that any qualitative or quantitative alteration in the spatiotemporal extents or characteristics of the cryosphere has the potential to affect global or regional air circulation patterns, sea and air temperatures, ocean currents, and global sea level. This highlights the need for continuous monitoring of cryosphere at different spatiotemporal scales using various field-based and remote-sensing-based approaches to estimate the ever-changing dynamics of the cryosphere. However, year-round in situ cryospheric monitoring is expensive and limited by hostile climate, logistic management, inadequacy 
of skilled manpower, and funding support. This makes remote sensing a practical substitute for meeting the growing needs of cryospheric research [1].

Remote sensing has been extremely useful for collecting information on remote, difficult-to-reach areas, which comprises much of the cryosphere. Satellite-based remote sensors are powerful tools for monitoring the environment. However, effective utilization of available satellite data for cryospheric research also demands for a tradeoff between spatial resolution and temporal revisit. For example, to monitor a glacial lake susceptible to outburst flooding, one needs high temporal resolution which may only be available with coarse spatial resolution satellite images. If the glacial lake is spread across just a few tens or hundreds of meters squared, compromising too much on the spatial resolutions is also not ideal. Moreover, such satellite images can prove to be too coarse for studying individual smaller-sized alpine glaciers and snow fields and are subject to extensive cloud cover the majority of the year [2]. This also puts a constraint on the accuracy and reliability of the results in the absence of sufficient field validations [3]. Manned aircrafts are an excellent source of aerial imagery, yet their usage is limited by high exploitation costs, lack of operational infrastructure, can prove dangerous due to extreme and changing weather, and increase intrusion on wildlife $[4,5]$. In such scenarios, unmanned aerial vehicles (UAVs) have emerged as a low-cost, flexible, and safer alternative. Beyond the practical benefits of cost and safety, UAVs have a temporal advantage since they can be deployed more regularly, provide spatial resolution at centimeter scales, and can view the surface under cloud cover. Most importantly, UAVs can be equipped with a range of possible light-weight sensors (photogrammetric RGB cameras, multispectral, hyperspectral, thermal, LiDAR, atmospheric, and gravimetric sensors) as per user requirements and research needs. In recent years, UAVs have been increasingly used as a remote sensing platform for studying cryospheric components such as snow cover, glaciers, ice sheets, permafrost, and other polar targets such as wild life, landforms, peatlands and sea ice [6]. Since a review article [1] that covered the early developments of UAV uses for a single cryospheric component, i.e., glaciers, was published four years ago, there has been a significant research gap of such comprehensive reviews covering either glaciers or the cryosphere as a whole. The present review summarizes the recent cryospheric applications of UAVs between 2014 and 2019 that were not covered in any previous review. Hardware, software, and analysis techniques have immensely evolved in the past four years and vary among the applications. Our aim is to provide a first-hand literature survey of these recent articles, identify the present and future niche areas, and summarize suggestions for successful UAV usage based on explicit accounts of experience. This paper aims to promote a standard that will provide upcoming researchers interested in using UAV technology for cryospheric research the background information and new perspectives to begin with. We start this review by first defining our search method, followed by tabulating the identified studies in chronological order, and then systematically discussing them under various cryospheric realms. We further discuss the UAV and sensor hardware, data acquisition and processing software in terms of popularity for cryospheric applications and revisit the existing UAV flying regulations in cold regions of the world. Finally, we suggest potential future applications and provide technical recommendations based on the reviewed papers. To the best of our knowledge, this paper is the first review of applications of UAV technology dedicated to cryospheric research.

\section{Search Methods}

The papers included in this review were found by utilizing the Clark University Library online discovery tool and Google Scholar to search for several combinations of keywords such as "Arctic", "Antarctica", “UAV", “UAS", "unmanned aerial", "drone", "polar", "glacier", "permafrost", , ice sheet", "snow cover", and "glaciology". Beyond the word searches, we followed papers referenced in published studies that would also be applicable to the criterion. Materials including peer-reviewed articles, conference proceedings, theses and dissertations utilizing UAVs for cryospheric research were consulted. The review considered studies published from 2014 to 2019. Criteria of article inclusion were studies that focused on environmental aspects for cryosphere or polar disciplines and that UAVs were a 
meaningful tool for research. Feasibility studies for UAVs in cryosphere studies were also considered. Studies that included UAV datasets but only as ancillary information without detailed description of flights were disregarded. Studies previously covered in the UAV review by Bhardwaj et al. [1] were not repeated here. All of the papers collected underwent a thorough review focused on their UAV methods, produced datasets and accounts of experience or recommendations. Thus, we collected 103 applicable papers in this manner with the goal of providing a comprehensive sample and holistic review of the literature.

\section{Cryospheric Applications}

UAVs provide a diverse array of opportunities for data collection applicable to many sectors of the cryosphere. A summary of the studies which applied UAVs to study cryosphere during 2014-2019 are listed in Table 1. There are many possibilities of UAV-enabled data collection could benefit areas such as lower atmosphere monitoring of aerosols and black carbon, atmospheric energy and gas concentrations, oceanic and sea ice processes, glacier dynamics, and ecosystem resilience. The following case studies describe many applications that have been recently attempted and published.

Table 1. Summary of application studies of unmanned aerial vehicles (UAVs) in cryospheric disciplines. The articles mentioned here were published online between 2014 and 2019.

\begin{tabular}{|c|c|c|c|}
\hline Study & Location & UAV Platform & Highlights \\
\hline Lucieer et al. (2014) [7] & $\begin{array}{l}\text { Windmill Islands, } \\
\text { Antarctica }\end{array}$ & $\begin{array}{l}\text { MikroKopter } \\
\text { OktoKopter }\end{array}$ & $\begin{array}{l}\text { Performed a single flight } \\
\text { to capture } \\
\text { micro-topography } \\
\text { (bryophytes and lichens) } \\
\text { of moss beds. }\end{array}$ \\
\hline Turner et al. (2014) [8] & $\begin{array}{l}\text { Windmill Islands, } \\
\text { Antarctica }\end{array}$ & $\begin{array}{l}\text { MikroKopter } \\
\text { OktoKopter }\end{array}$ & $\begin{array}{l}\text { Flew multiple sensors to } \\
\text { investigate physiological } \\
\text { state of moss ecosystems } \\
\text { including a visible } \\
\text { camera ( } 1 \mathrm{~cm} / \text { pixel }), \text { a } 6 \\
\text { band multispectral } \\
\text { camera ( } 3 \mathrm{~cm} / \text { pixel), } \\
\text { and a thermal infrared } \\
\text { camera ( } 10 \mathrm{~cm} / \text { pixel). }\end{array}$ \\
\hline $\begin{array}{l}\text { Bollard-Breen et al. } \\
\text { (2015) [9] }\end{array}$ & $\begin{array}{l}\text { McMurdo Dry valleys, } \\
\text { Antarctica }\end{array}$ & Custom-built fixed wing & $\begin{array}{l}\text { Used a UAV to identify } \\
\text { cyanobacterial mats, } \\
\text { estimate their extent and } \\
\text { discriminate between } \\
\text { different mat types. They } \\
\text { were able to detect } \\
\text { human disturbances on } \\
\text { the mat and } \\
\text { recommended using this } \\
\text { technology to monitor } \\
\text { human impact on the } \\
\text { fragile ecosystem. }\end{array}$ \\
\hline Goebel et al. (2015) [10] & Cape Shirreff, Antarctica & $\begin{array}{l}\text { Microdrone md4-1000, } \\
\text { Aerial Imaging Solutions } \\
\text { APQ-18, Aerial Imaging } \\
\text { Solutions APH-22 }\end{array}$ & $\begin{array}{l}\text { Tested three UAV and } \\
\text { camera systems to } \\
\text { compare performance in } \\
\text { collecting abundance } \\
\text { and disturbance } \\
\text { information on a few } \\
\text { penguin and seal } \\
\text { population samples. }\end{array}$ \\
\hline
\end{tabular}


Table 1. Cont.

\begin{tabular}{|c|c|c|c|}
\hline Study & Location & UAV Platform & Highlights \\
\hline $\begin{array}{l}\text { Vander Jagt et al. (2015) } \\
\text { [11] }\end{array}$ & Tasmania, Australia & Doidworx SkyJiB & $\begin{array}{l}\text { Used imagery obtained } \\
\text { from UAS in conjunction } \\
\text { with photogrammetric } \\
\text { techniques to resolve } \\
\text { spatially continuous } \\
\text { snow depths using } \\
\text { snow-covered and } \\
\text { snow-free RGB images. }\end{array}$ \\
\hline Jonassen et al. (2015) [12] & Weddell Sea, Antarctica & $\begin{array}{l}\text { Multiplex and Mavionics } \\
\text { custom Fixed Wings and } \\
\text { a custom quadcopter }\end{array}$ & $\begin{array}{l}\text { Used multirotor and } \\
\text { fixed wing UAVs to } \\
\text { collect stratified air } \\
\text { samples and physical } \\
\text { properties for } \\
\text { atmospheric boundary } \\
\text { layer profiling above sea } \\
\text { ice. }\end{array}$ \\
\hline Steiner et al. (2015) [13] & Liring Glacier, Nepal & Swinglet CAM & $\begin{array}{l}\text { Utilized updated } \\
\text { meteorological and in } \\
\text { situ measurements to } \\
\text { model ice cliff } \\
\text { backwasting with the aid } \\
\text { of a DSM produced by } \\
\text { previously published } \\
\text { flights [14]. }\end{array}$ \\
\hline $\begin{array}{l}\text { Cimoli 2015, Cimoli et al. } \\
(2017)[15,16]\end{array}$ & Longyearbyen, Svalbard & $\begin{array}{l}\text { Walkera X350 Pro, DJI } \\
\text { S900, custom-built } \\
\text { octocopter }\end{array}$ & $\begin{array}{l}\text { Sought to assess the } \\
\text { feasibility of UAS SfM } \\
\text { for depicting snow depth } \\
\text { variability. Expected to } \\
\text { fly at six locations but } \\
\text { only completed one due } \\
\text { to "UAS failure." } \\
\text { Suggested pilots to be } \\
\text { prepared to fly manually } \\
\text { in Arctic locations. }\end{array}$ \\
\hline $\begin{array}{l}\text { Westoby et al. (2015. } \\
2016) \\
{[17,18]}\end{array}$ & Patriot Hills, Antarctica & Unspecified fixed wing & $\begin{array}{l}\text { Orthomosaic and DSM } \\
\text { produced by a UAV } \\
\text { flight to aid in upscaling } \\
\text { from patch scale } \\
\text { sedimentological } \\
\text { characterization and } \\
\text { quantify short-term } \\
\text { surface evolution of a } \\
\text { moraine complex. }\end{array}$ \\
\hline $\begin{array}{l}\text { De Michele et al. (2015, } \\
\text { 2016)* }[19,20]\end{array}$ & Val Grosina Vallu, Italy & SenseFly Swinglet CAM & $\begin{array}{l}\text { Investigated UAV } \\
\text { capability of detecting } \\
\text { centimeter-resolution } \\
\text { snow depth distribution } \\
\text { compared to ground } \\
\text { measurements for an } \\
\text { alpine region. }\end{array}$ \\
\hline
\end{tabular}


Table 1. Cont.

\begin{tabular}{|c|c|c|c|}
\hline Study & Location & UAV Platform & Highlights \\
\hline Stuchlik et al. (2016) [21] & $\begin{array}{l}\text { Nordenskiöldbreen } \\
\text { glacier, Svalbard }\end{array}$ & Custom multirotor & $\begin{array}{l}\text { Created example } \\
\text { products to demonstrate } \\
\text { possible uses of UAVs } \\
\text { including an RGB and IR } \\
\text { orthomosaic of a } \\
\text { proglacial river system. } \\
\text { This is a proof-of-concept } \\
\text { manuscript. }\end{array}$ \\
\hline Buri et al. (2016) [22] & Liring Glacier, Nepal & Swinglet CAM & $\begin{array}{l}\text { Created a gridded cliff } \\
\text { backwasting model } \\
\text { including DSM produced } \\
\text { from previously } \\
\text { published flights [14]. }\end{array}$ \\
\hline
\end{tabular}

Used a UAV-derived

DSM to describe

Pederson et al. (2016)

[23]

Zackenberg, Greenland Unspecified

landscape features for investigating variations in snow distribution amongst vegetation types.

Investigated practical upgrades with the evolution of RGB + NIR

Boesch et al. (2016) [24] Brämabühl, Switzerland

Ascending Technologies sensor hardware and (AscTec) Falcon 8 SfM software for UAV and manned aircraft for improved reconstructions of snow height in an Alpine area.

Used a UAV to produce a detailed map of complex flutings to supplement a study on the

Ewertowski et al. (2016) Nordenskiöldbreen [25] glacier, Svalbard

Unspecified quadcopter geomorphology of terrestrial margins within the foreland of a tidewater polythermal glacier.

A single UAV survey was flown to map Evans et al (2016) [26] Fláajökull glacier, Iceland Unspecified quadcopter that have recently evolved (since 1989) at a glacier snout.

UAV imagery used to investigate the

Tonkin et al. (2016) [27] Austre Lovénbreen, DJI S800 degradation of an ice-cored lateral-frontal moraine. 
Table 1. Cont.

\begin{tabular}{|c|c|c|c|}
\hline Study & Location & UAV Platform & Highlights \\
\hline Harder et al. (2016) [28] & $\begin{array}{l}\text { Canadian Rocky } \\
\text { Mountains and } \\
\text { Saskatchewan }\end{array}$ & Sensefly eBee & $\begin{array}{l}\text { Quantified snow depth } \\
\text { using a UAV with RTK } \\
\text { technology on different } \\
\text { terrain types (prairie and } \\
\text { alpine) and tested } \\
\text { accuracy. }\end{array}$ \\
\hline Vincent et al. (2016) [29] & $\begin{array}{l}\text { Changri Nup Glacier, } \\
\text { Nepal }\end{array}$ & Sensefly eBee & $\begin{array}{l}\text { Glacier surface mass } \\
\text { balance is modeled } \\
\text { combining UAV, } \\
\text { terrestrial } \\
\text { photogrammetry, } \\
\text { satellite, and in situ } \\
\text { measurements to } \\
\text { investigate debris-cover } \\
\text { influence using data } \\
\text { from previously } \\
\text { published flights (i.e. } \\
\text { [29]). }\end{array}$ \\
\hline $\begin{array}{l}\text { Kraaijenbrink et al. } \\
\text { (2016) [30] }\end{array}$ & Liring Glacier, Nepal & Sensefly eBee & $\begin{array}{l}\text { Collected optical RGB } \\
\text { and thermal data on } \\
\text { separate flights } \\
\text { surveying a } \\
\text { debris-covered glacier } \\
\text { and compared to in situ } \\
\text { and satellite sources. }\end{array}$ \\
\hline $\begin{array}{l}\text { Brun et al. }(2016,2018) \\
{[31,32]}\end{array}$ & $\begin{array}{l}\text { Liring Glacier, Changri } \\
\text { Nup Glacier, Nepal }\end{array}$ & $\begin{array}{l}\text { Sensefly Swinglet CAM, } \\
\text { Sensefly eBee }\end{array}$ & $\begin{array}{l}\text { Quantified total } \\
\text { contribution of ice cliff } \\
\text { backwasting to the net } \\
\text { ablation of a glacier } \\
\text { tongue via } \\
\text { UAV-collected } \\
\text { backwasting and surface } \\
\text { thinning based on data } \\
\text { from previously } \\
\text { published flights (i.e. } \\
[13,29]) \text {. }\end{array}$ \\
\hline $\begin{array}{l}\text { Bühler et al. }(2016,2017) \\
{[33,34]}\end{array}$ & $\begin{array}{l}\text { Davos, Switzerland and } \\
\text { Lizum, Austria }\end{array}$ & $\begin{array}{l}\text { Ascending Technologies } \\
\text { (AscTec) Falcon 8, } \\
\text { Multiplex Mentor Elapor }\end{array}$ & $\begin{array}{l}\text { Photogrammetrically } \\
\text { estimated snow depth } \\
\text { with UAVs on various } \\
\text { surfaces including } \\
\text { exposed alpine peak, } \\
\text { sheltered valley area, } \\
\text { and homogenous snow } \\
\text { surfaces and discussed } \\
\text { UAV performance in } \\
\text { several scenarios }\end{array}$ \\
\hline $\begin{array}{l}\text { Rümmler et al. (2016, } \\
\text { 2018) [35,36] }\end{array}$ & $\begin{array}{l}\text { South Shetland Islands, } \\
\text { Antarctica }\end{array}$ & $\begin{array}{l}\text { Mikrokopter MK ARF } \\
\text { Okto XL }\end{array}$ & $\begin{array}{l}\text { Recorded behavioral } \\
\text { reactions of Gentoo and } \\
\text { Adélie penguins to a } \\
\text { UAV flown at different } \\
\text { altitudes. Disturbance } \\
\text { was visible when flown } \\
\text { at a upper level of } 30 \mathrm{~m} \\
\text { and } 50 \mathrm{~m} \text { above ground } \\
\text { respectively. }\end{array}$ \\
\hline
\end{tabular}


Table 1. Cont.

\begin{tabular}{|c|c|c|c|}
\hline Study & Location & UAV Platform & Highlights \\
\hline Lambiel et al. (2017) [37] & $\begin{array}{l}\text { La Roussette rock glacier, } \\
\text { Switzerland }\end{array}$ & SenseFly eBee RTK & $\begin{array}{l}\text { Preliminary results of } \\
\text { orthomosaics collected of } \\
\text { a remote, difficult to } \\
\text { reach, rapidly moving, } \\
\text { newly discovered rock } \\
\text { glacier within the Valais } \\
\text { Alps. }\end{array}$ \\
\hline $\begin{array}{l}\text { Dall'Asta et al. (2017) } \\
\text { [38] }\end{array}$ & $\begin{array}{l}\text { Valtournenche Valley, } \\
\text { Italy }\end{array}$ & $\begin{array}{l}\text { Swinglet CAM, SenseFly } \\
\text { eBee RTK }\end{array}$ & $\begin{array}{l}\text { Discussed the } \\
\text { performance of GCP and } \\
\text { RTK derived UAV } \\
\text { products for depicting } \\
\text { displacement and } \\
\text { characteristics of a rock } \\
\text { glacier. }\end{array}$ \\
\hline
\end{tabular}

Sensors mounted on a UAV collected several aerosol properties using a condensation nuclei counter, chemical filter sampler,

Telg et al. (2017) [39] Ny-Alesund, Svalbard Manta fixed wing three-wavelength aerosol absorption photometer, printed optical particle spectrometer, miniature scanning sun photometer, $\mathrm{HC} 2$ temperature and relative humidity probe.

Tested a novel method for on-demand snow

Miziński and Niedzielski Izerskie Mountains, (2017) [40] Poland

Sensefly eBee and Swinglet CAM depth mapping that omitted artificial GCPs though the method was found to be less accurate than including GCPs.

Mixed methods study including terrestrial LiDAR, satellite, ground penetrating radar, and high-resolution maps from RGB-flown UAV to analyze activity of a pulsing glacier.

UAV orthophoto and DSM supplemented QuickBird imagery to provide information on surficial deposits and associated landforms (i.e., fluvio-deltaic terraces) to support study on an ice-dammed lake. 
Table 1. Cont.

\begin{tabular}{|c|c|c|c|}
\hline Study & Location & UAV Platform & Highlights \\
\hline $\begin{array}{l}\text { Mustafa et al. (2017, } \\
\text { 2018) }[43,44]\end{array}$ & $\begin{array}{l}\text { South Shetland Islands, } \\
\text { Antarctica }\end{array}$ & $\begin{array}{l}\text { Mikrokopter MK ARF } \\
\text { Okto XL }\end{array}$ & $\begin{array}{l}\text { Tested census techniques } \\
\text { of penguin populations } \\
\text { and found that NIR can } \\
\text { be useful for } \\
\text { distinguishing guano } \\
\text { once vegetation signals } \\
\text { are removed using } \\
\text { NDVI, which has been } \\
\text { helpful for identifying } \\
\text { individual breeding } \\
\text { pairs. Also reviewed } \\
\text { wildlife responses to } \\
\text { UAV activities. }\end{array}$ \\
\hline
\end{tabular}

Three fractional snow cover mapping algorithms were tested on UAV and satellite

Liang et al. (2017) [45] Tibetan Plateau, China $\quad$ DJI Inspire 1 Pro data. A back-propagation artificial neural network model performed the best in the plateau's complex terrain.

RGB flight data that originally appeared in Smith et al. (2017) [46] $\quad \begin{aligned} & \text { Kangerlussuaq, } \\ & \text { Greenland }\end{aligned}$ Ryan et al. [47] provided catchment boundaries, surface drainage patterns, and snow cover for Rio Behar.

A thesis using the flights previously provided by Kraaijenbrink to investigate methodology on measuring ice cliff backwasting.

A thesis exploring the possibility of physically using UAVs for Arctic research. Includes

Ader and Axelsson (2017) [49]

Tarfala, Sweden

DJI Phantom 4

Aeryon Scout interviews with UAV industry representatives and scientists, and test flights performed by unexperienced pilots as a measure of ease in applicability.

UAV was used to reproduce ground elevations in peatland area and evaluate the role of vegetation and surface complexity. 
Table 1. Cont.

\begin{tabular}{|c|c|c|c|}
\hline Study & Location & UAV Platform & Highlights \\
\hline Burkhart et al. (2017) [51] & Summit, Greenland & Cryowing & $\begin{array}{l}\text { Collected UAV-derived } \\
\text { albedo over the } \\
\text { Greenland ice sheet } \\
\text { coincident with the } \\
\text { MODIS sensor overpass } \\
\text { for validation. }\end{array}$ \\
\hline $\begin{array}{l}\text { Bernard et al. (2017, } \\
\text { 2017) }[52,53]\end{array}$ & $\begin{array}{l}\text { Austre Lovén glacier, } \\
\text { Svalbard }\end{array}$ & DJI Phantom 3 & $\begin{array}{l}\text { Used UAVs to analyze } \\
\text { ice, snowpack and } \\
\text { moraine dynamics with } \\
\text { hydrology through } \\
\text { repeated UAV survey a } \\
\text { few days apart to capture } \\
\text { a quickly changing } \\
\text { environment. }\end{array}$ \\
\hline
\end{tabular}

Mapped a polythermal glacier for

Ely et al. (2017) [54] Isfallsglaciären, Sweden Custom hexactopter geomorphological characteristics including moraines, fans, channels and flutes.

Flew a UAV to identify mass and body

Krause et al. (2017) [55] Cape Shirreff, Antarctica

Aerial Imaging Solutions APH-22 conditions of pinnipeds at target altitudes of 23, 30 and $45 \mathrm{~m}$ above ground level.

Collected hyperspectral high-resolution imagery

Malenovský et al. (2017) Windmill Islands, [56] Antarctica

Custom-built octocopter to estimate moss bed health via machine-learning support vector regressions.

Detect and quantified periglacial landforms such as scarps, taluses, Dabski et al. (2017) [57] $\quad \begin{aligned} & \text { King George Island, } \\ & \text { Antarctica }\end{aligned}$

PW-ZOOM a protalus rampart, solifuction sheets, bedrock outcrops, and more from an orthomosaic and DSM.

Combined UAV and satellite imagery with ice flow modelling to analyze calving activity of a marine-terminating glacier.

Found heterogenous patterns of glacial volume change, surface

Wigmore and Mark (2017) [2]

Llaca Glacier, Peru

Custom-built hexacopter cities, and proglacial lake changes via a hexacopter designed for high-altitude missions. 
Table 1. Cont.

\begin{tabular}{|c|c|c|c|}
\hline Study & Location & UAV Platform & Highlights \\
\hline Seier et al. (2017) [59] & Pasterze Glacier, Austria & QuestUAV & $\begin{array}{l}\text { Used a UAV along with } \\
\text { electrical resistivity } \\
\text { tomography for surface } \\
\text { change detection of a } \\
\text { glacier terminus. } \\
\text { Provided a great } \\
\text { example of careful } \\
\text { accuracy assessment for } \\
\text { UAV DSMs. }\end{array}$ \\
\hline
\end{tabular}

Collected glacier DSMs in summer, autumn, and winter to investigate the accuracy of

Gindraux et al. (2017) Multiple glaciers, [60] Switzerland

Sensefly eBee

UAV-derived DSMs. Found that GCPs increase accuracy until a threshold is met and the presence of fresh snow decreased DSM accuracy.

Obtained accurate fine-scale resolution of albedo over a sample of the Greenland ice sheet.

Sought to understand precursory signals of an observed collapse of Scaioni et al. $(2017,2018)$ $[62,63]$ Forni Glacier, Italy SenseFly Swinglet CAM glacier tongue and discussed challenges of SfM applications for alpine glacier change.

Assessed samples of eleven seabird species behavioral reaction to UAV flown within close

Weimerskirch et al. Crozet Islands, South (2018) [64] Indian Ocean

DJI Phantom 3 vicinity at different altitudes. Found reactions above $50 \mathrm{~m}$ relative to individuals provided negligible impacts.

Compared UAV flown RGB to aerial RGB + NIR imagery for identifying morphometric and topological features of ice-wedge polygonal networks.

Flew over the lower 16 $\mathrm{km}$ ablation area of a glacier at an altitude of $800 \mathrm{~m}$ to describe the structural, geomorphological and hydrological features of terminus. 
Table 1. Cont.

\begin{tabular}{|c|c|c|c|}
\hline Study & Location & UAV Platform & Highlights \\
\hline $\begin{array}{l}\text { Cooper et al. }(2018)^{*} \\
{[67,68]}\end{array}$ & $\begin{array}{l}\text { Kangarussuaq } \\
\text { Greenland }\end{array}$ & Unspecified quadcopter & $\begin{array}{l}\text { UAV supplied a } \\
\text { supplementary } \\
\text { orthomosaic and DSM } \\
\text { for study on cryoconite } \\
\text { holes. }\end{array}$ \\
\hline Yang et al. $(2018)^{*}[69,70]$ & $\begin{array}{l}\text { Kangerlussuaq, } \\
\text { Greenland }\end{array}$ & Skywalker X8 & $\begin{array}{l}\text { RGB flight data that } \\
\text { originally appeared in } \\
\text { [47] assisted in validating } \\
\text { accuracy of supraglacial } \\
\text { stream-river delineations } \\
\text { from satellite imagery. }\end{array}$ \\
\hline de Boer et al. (2018) [71] & $\begin{array}{l}\text { Oliktok Point, Alaska, } \\
\text { USA }\end{array}$ & $\begin{array}{l}\text { QuestUAV DataHawk } \\
\text { and Pilatus }\end{array}$ & $\begin{array}{l}\text { Described the } \\
\text { UAV-enabled tasks } \\
\text { performed under the US } \\
\text { DOE Atmospheric } \\
\text { Radiation Measurement } \\
\text { program, including data } \\
\text { collected on atmospheric } \\
\text { aerosols, } \\
\text { thermodynamics, } \\
\text { and albedo over sea ice. }\end{array}$ \\
\hline Fugazza et al. (2018) [72] & Forni Glacier, Italy & $\begin{array}{l}\text { Sensefly Swinglet CAM } \\
\text { and custom quadcopter }\end{array}$ & $\begin{array}{l}\text { Analyzed multi-year } \\
\text { surveys to evaluate } \\
\text { glacier thinning rate and } \\
\text { for mapping hazards } \\
\text { related to a collapse } \\
\text { event. }\end{array}$ \\
\hline
\end{tabular}

Flown twice a day for twelve days over $\begin{array}{ll}\text { Jouvet et al. (2018) [73] } & \begin{array}{l}\text { Bowdoin Glacier, } \\ \text { Greenland }\end{array}\end{array}$

Firefly 6 vertical take-off and landing hybrid UAV
Bowdoin Glacier to monitor non-linear plume dynamics at the calving front.

Subtracted a UAV DSM from a previously available DSM to estimate river ice thickness. Orthomosaic produced to map river ice for an ice jam and anchor ice dams.

Evaluated methodologies for automated mapping of relict, sorted patterned ground characteristic of mature periglacial landforms using off-the-shelf fixed wing and multirotor systems. 
Table 1. Cont.

\begin{tabular}{|c|c|c|c|}
\hline Study & Location & UAV Platform & Highlights \\
\hline Tan et al. (2018) [76] & Scott Base, Antarctica & Unspecified multirotor & $\begin{array}{l}\text { Preliminary results of an } \\
\text { investigation into } \\
\text { feasibility to utilize } \\
\text { airborne radar onboard a } \\
\text { UAV to map out snow } \\
\text { depth on sea ice in } \\
\text { Antarctica. }\end{array}$ \\
\hline $\begin{array}{l}\text { Gonzalez et al. (2018) } \\
\text { [77] }\end{array}$ & $\begin{array}{l}\text { Tuktoyaktuk Coastal } \\
\text { Plain, Canada }\end{array}$ & Unspecified & $\begin{array}{l}\text { Preliminary results of } \\
\text { quantitative } \\
\text { morphological } \\
\text { description of pingos } \\
\text { (conical ice-cored hills) } \\
\text { via UAV and satellite } \\
\text { imagery. }\end{array}$ \\
\hline Midgley et al. (2018) [78] & $\begin{array}{l}\text { Midtre Lovénbreen } \\
\text { glacier, Svalbard }\end{array}$ & DJI S800 & $\begin{array}{l}\text { Compared a LiDAR } \\
\text { topographic dataset to a } \\
\text { UAV DSM to study } \\
\text { moraine evolution and } \\
\text { glacial landform } \\
\text { response to climate. }\end{array}$ \\
\hline $\begin{array}{l}\text { Florinsky and } \\
\text { Bliakharskii (2018) [79] }\end{array}$ & $\begin{array}{l}\text { Progress Station, } \\
\text { Antarctica }\end{array}$ & Geoscan 201 fixed wing & $\begin{array}{l}\text { Presented a novel } \\
\text { approach for revealing } \\
\text { hidden crevasses based } \\
\text { on geomorphometric } \\
\text { treatment of } \\
\text { high-resolution glacier } \\
\text { DSMs. }\end{array}$ \\
\hline $\begin{array}{l}\text { Bliakharskii and } \\
\text { Florinsky (2018) [80] }\end{array}$ & $\begin{array}{l}\text { Progress Station, } \\
\text { Antarctica }\end{array}$ & Geoscan 201 fixed wing & $\begin{array}{l}\text { Based on the same flight } \\
\text { that appears in Florinsky } \\
\text { and Bliakharskii [79], } \\
\text { expands on crevasse } \\
\text { identification and } \\
\text { observations of a surface } \\
\text { collapse event of Dålk } \\
\text { Glacier. }\end{array}$ \\
\hline Isacsson (2018) [81] & Tarfala, Sweden & $\begin{array}{l}\text { DJI Phantom } 4^{* *} \\
{ }^{* *} \text { Discussed the DJI } \\
\text { Phantom } 4 \text { throughout } \\
\text { the paper. One sentence } \\
\text { stated the imagery used } \\
\text { was collected by a DJI } \\
\text { Phantom } 3, \text { we assume } \\
\text { here this was a } \\
\text { typographic error. }\end{array}$ & $\begin{array}{l}\text { A sibling thesis to Ader } \\
\text { and Axelssson [46], } \\
\text { investigated the } \\
\text { performance of UAVs in } \\
\text { mapping snow surface } \\
\text { distance and snow layer } \\
\text { depth estimation } \\
\text { comparing Agisoft } \\
\text { Photoscan and Pix } 4 \text { d } \\
\text { reconstructions with } \\
\text { various sensors. }\end{array}$ \\
\hline $\begin{array}{l}\text { Attalla and Tang (2018) } \\
\text { [82] }\end{array}$ & Tarfala, Sweden & N/A & $\begin{array}{l}\text { A thesis that more } \\
\text { thoroughly described } \\
\text { engineering aspects of } \\
\text { applying LiDAR and } \\
\text { ultrasonic sensor on a } \\
\text { UAV for measuring } \\
\text { heights of ablation stakes. } \\
\text { Sensors were tested in a } \\
\text { lab setting and a UAV } \\
\text { was not flown. }\end{array}$ \\
\hline
\end{tabular}


Table 1. Cont.

\begin{tabular}{|c|c|c|c|}
\hline Study & Location & UAV Platform & Highlights \\
\hline Adams et al. (2018) [83] & Tuxer Alps, Austria & Multiplex Mentor Elapor & $\begin{array}{l}\text { Twelve UAV flights of a } \\
\text { snow-covered slope } \\
\text { confirmed that both RGB } \\
\text { and NIR UAV-derived } \\
\text { DSMs provide highest } \\
\text { accuracy under full } \\
\text { sunlight conditions, } \\
\text { while NIR provided } \\
\text { more accurate snow } \\
\text { DSMs under poorly } \\
\text { illuminated conditions. }\end{array}$ \\
\hline Luo et al. (2018) [84] & $\begin{array}{l}\text { Kunlun Mountains, } \\
\text { China }\end{array}$ & DJI Inspire 1 & $\begin{array}{l}\text { Measured the thermal } \\
\text { influence of power } \\
\text { transmission poles and } \\
\text { railroads on permafrost } \\
\text { slopes via an RGB and } \\
\text { IR-enabled UAV. They } \\
\text { recorded variability of } \\
\text { heat transfer that could } \\
\text { create unstable } \\
\text { foundations for the } \\
\text { infrastructure. They } \\
\text { recommend image } \\
\text { overlap to be at least } 90 \% \\
\text { for successful thermal } \\
\text { mosaicking. }\end{array}$ \\
\hline
\end{tabular}

Opportunistically observed the behavior of three adult male polar Barnas et al. (2018) [85] Manitoba, Canada Trimble UX5 bears and discussed the use and challenges of UAVs use for surveying polar bears.

Flew a UAV beyond line of site to identify fauna,

Zmarz et al. (2018) [4] King George Island, Antarctica

PW-ZOOM flora, and landforms to successfully monitor key elements of a polar ecosystem on the remote Penguin Island.

Collected information on surface velocity, brightness, roughness, and DSM differencing of the ablation region of Morteratch Glacier.

UAV was flown with both RGB and IR to improve UAV surveying potential for estimating glacial debris thickness via thermal signatures. 
Table 1. Cont.

\begin{tabular}{|c|c|c|c|}
\hline Study & Location & UAV Platform & Highlights \\
\hline Kraaijenbrink 2018 [88] & Liring Glacier, Nepal & Sensefly Swinglet CAM & $\begin{array}{l}\text { Two field campaigns } \\
\text { flown to assess the } \\
\text { magnitude of the } \\
\text { downwasting of a } \\
\text { debris-covered glacial } \\
\text { tongue and the average } \\
\text { glacier movement over } \\
\text { the monsoon season. }\end{array}$ \\
\hline Kim and Kim (2018) [89] & East Siberian Sea & $\begin{array}{l}\text { DJI multirotor } \\
\text { (unspecified) }\end{array}$ & $\begin{array}{l}\text { Proposed a method of } \\
\text { detecting incorrect } \\
\text { matches among images } \\
\text { prior to correcting DSMs } \\
\text { derived from UAV flown } \\
\text { over sea ice. }\end{array}$ \\
\hline
\end{tabular}

Mapped impact hollows

Kizyakov et al. (2018) Siberia, Russia $\quad$ Unspecified
[90]

resulting from gas

emission craters in permafrost zones using a UAV.

Quantified permafrost thaw slump dynamics,

van der Sluijs et al. (2018) Northwest Territories, [91] Canada

A Sensefly, 2 Badatech, 2 DJI UAVs estimated volumes of downslope sediment transfer and identified stratification features along a headwall.

Compared snow depth measurements of UAV with a high-resolution MultiStation

Avanzi et al. (2018) [92] Belvedere glacier, Italy Custom hexacopter laser-scanner, found similar results within centimeter accuracy of spatial distribution of seasonal, dense snowpack.

Based on the same flight data in [4], this study further provided a

Korczak-Abshire et al. King George Island, (2018) [93]
PW-ZOOM census of local seabird and seal populations on Antarctic islands that would otherwise be difficult to access.

Investigates accuracy of multitemporal snow depth measurements over diverse microtopographic and vegetation cover terrain in relation to photogrammetric theory. 
Table 1. Cont.

\begin{tabular}{|c|c|c|c|}
\hline Study & Location & UAV Platform & Highlights \\
\hline $\begin{array}{l}\text { Schirmer and Pomeroy } \\
(2018)^{*}[95,96]\end{array}$ & $\begin{array}{l}\text { Canadian Rocky } \\
\text { Mountains }\end{array}$ & Sensefly eBee & $\begin{array}{l}\text { Used SfM to develop } \\
\text { maps of snow depth and } \\
\text { snow cover to use as } \\
\text { proxies for snow water } \\
\text { equivalent, ablation } \\
\text { rates, and snow cover } \\
\text { depletion using data } \\
\text { from previously } \\
\text { published flights (i.e. } \\
\text { [26]). }\end{array}$ \\
\hline Cook et al. (2018) [97] & Western Greenland & DJI Phantom 2 & $\begin{array}{l}\text { Extracted still images } \\
\text { from UAV-collected RGB } \\
\text { video to obtain frequency, } \\
\text { coverage, and geometric } \\
\text { data of cryoconite holes. }\end{array}$ \\
\hline $\begin{array}{l}\text { Bash et al. }(2018,2019)^{*} \\
\text { [98-100] }\end{array}$ & Fountain Glacier, Canada & MikroKopter & $\begin{array}{l}\text { Measured daily and total } \\
\text { glacial ablation via UAV } \\
\text { reconstructions of a } \\
\text { glacier. Later tested an } \\
\text { enhanced temperature } \\
\text { index model of glacier } \\
\text { surface melt from this } \\
\text { data. }\end{array}$ \\
\hline
\end{tabular}

Flew a radar to resolve snow stratigraphy and a

Jenssen et al. $(2018,2019) \quad$ Multiple sites, Norway $\quad$ Foxtech Kraken dry snowpack and tested [101,102] its capability of detecting a person buried under $1.5 \mathrm{~m}$ of wet snow.

Vegetation and topography information collected by UAV was

Léger et al. (2019) [103] $\begin{aligned} & \text { Seward Peninsula, } \\ & \text { Alaska }\end{aligned}$ 3DR Solo UAV
combined with additional sensors to analyze permafrost parameters.

Compared satellite SAR, terrestrial radar Rohner et al. (2019) [104] $\begin{aligned} & \text { Eqip Sermia Glacier, } \\ & \text { Greenland }\end{aligned}$ interferometer, and UAV-derived velocity fields of a marine terminating glacier.

Subtracted snow-free from snow-covered UAV-derived DSMs during different snow conditions for snow depth calculations in a forest environment and additionally related this to leaf area index.

Lendzioch et al. (2019) [105]
Šumava National Park, Czech Republic
MicroKopter ARF-Okto XL 
Table 1. Cont.

\begin{tabular}{|c|c|c|c|}
\hline Study & Location & UAV Platform & Highlights \\
\hline $\begin{array}{l}\text { Hendrickx et al. (2019) } \\
\text { [106] }\end{array}$ & $\begin{array}{l}\text { Cliosses rock glacier, } \\
\text { Switzerland }\end{array}$ & Custom DJI F550 & $\begin{array}{l}\text { Created multiple } \\
\text { reconstructions of a rock } \\
\text { glacier with identical } \\
\text { inputs to test Agisoft } \\
\text { Photoscan SfM variation } \\
\text { among outputs. }\end{array}$ \\
\hline $\begin{array}{l}\text { Lamsters et al. (2019) } \\
\text { [107] }\end{array}$ & $\begin{array}{l}\text { Greenland, Antarctica, } \\
\text { Iceland }\end{array}$ & $\begin{array}{l}\text { DJI Phantom 3, DJI } \\
\text { Phantom 4, DJI Mavic } \\
\text { Air }\end{array}$ & $\begin{array}{l}\text { Discussed a collection of } \\
\text { experiences and } \\
\text { recommendations for } \\
\text { using off-the-shelf DJI } \\
\text { multirotors for DSM and } \\
\text { orthomosaic production } \\
\text { in polar environments. }\end{array}$ \\
\hline $\begin{array}{l}\text { Cook et al. }(2019) * \\
{[108,109]}\end{array}$ & Western Greenland & Steadidrone Mavrik & $\begin{array}{l}\text { Applied a novel } \\
\text { supervised classification } \\
\text { to a UAV-collected } \\
\text { multispectral } \\
\text { orthomosaic to map } \\
\text { algae cover on the } \\
\text { surface of the Greenland } \\
\text { ice sheet. }\end{array}$ \\
\hline
\end{tabular}

\footnotetext{
${ }^{*}$ Review was based on Discussions paper but recently published finalized versions are also cited.
}

The studies included in this review provided a wide range of research goals (Figure 1). Many of the UAV applications involved creating orthomosaics and Digital Surface Models (DSMs) from individual optical images. A smaller portion of the sampled studies collected wavelength data outside the visible spectrum, or aimed at characterizing aerosol or other atmospheric variables (e.g., [39,71]). An example of solar radiation measurements is Burkhart et al. [51], who fitted a UAV with upwelling and downwelling sensors to measure albedo on the Greenland Ice Sheet. Some other studies used the UAV itself as the experiment tool to gauge animal behavior [36,44,64]. Figures 1 and 2 show the distribution of topics covered and the geographic locations of the sampled studies, respectively. Glacier and snow cover stand out as the most popular research topics involving UAVs (Figure 1). These are followed by more generalized research themes focusing on geomorphology, vegetation, and animal behavior in cold regions. Atmospheric measurement applications of UAVs in cold regions are still in an early phase of publishing studies that address scientific questions rather than feasibility accounts but research in this field is certainly growing (e.g., [12,110]). Antarctica, Greenland and Norway were the most popular geographic areas covered using UAV sensors, followed by Canada and high mountain areas such as the Himalayas and the Alps (Figure 2). 


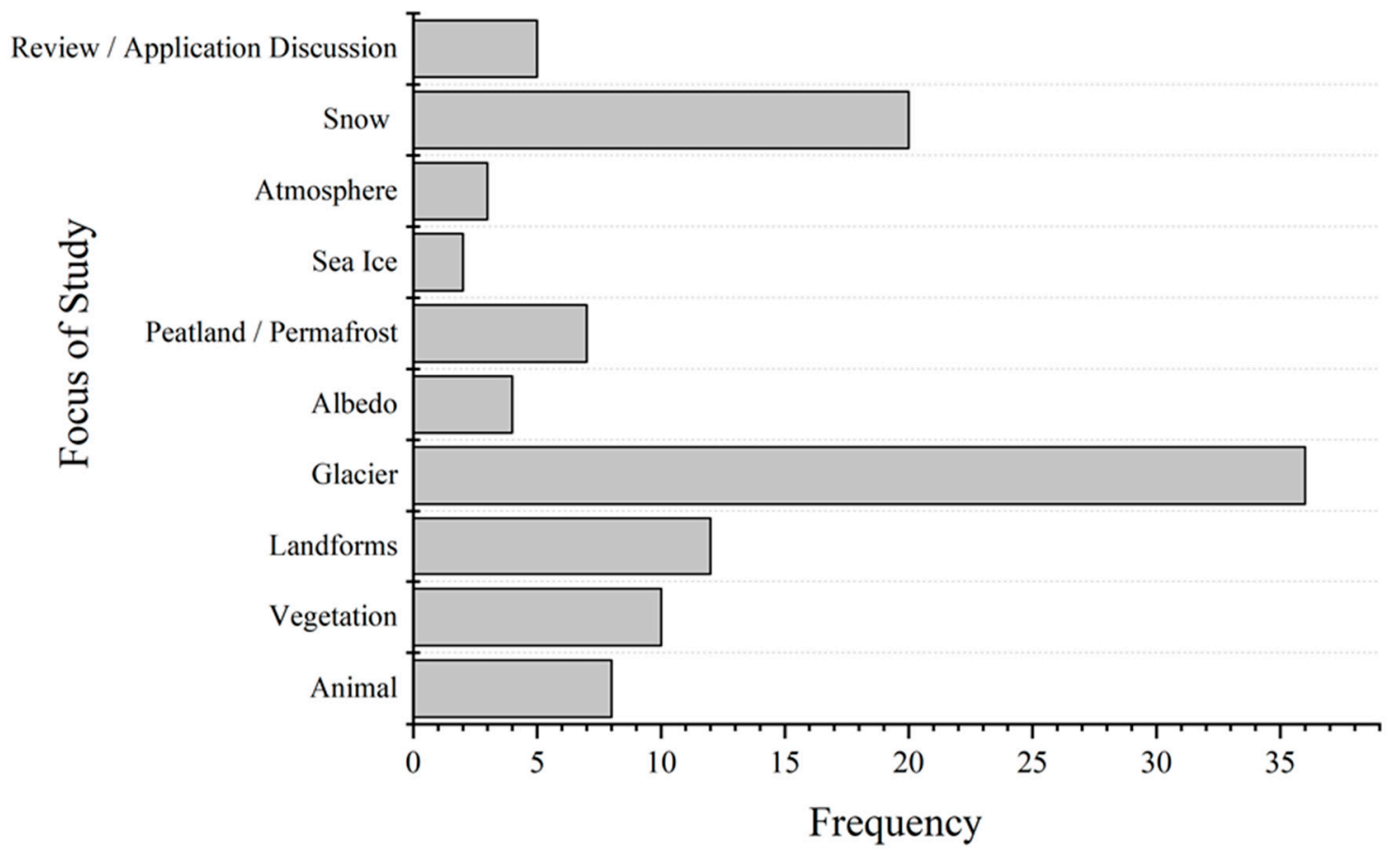

Figure 1. Distribution of main topics of recently published studies utilizing UAVs for cryosphere research. This plot consists of the studies that were published as complete research articles in peer-reviewed journals and conference proceedings, or as university degree theses made available online between 2014 and 2019.

\section{UAV Cryosphere Study Locations}

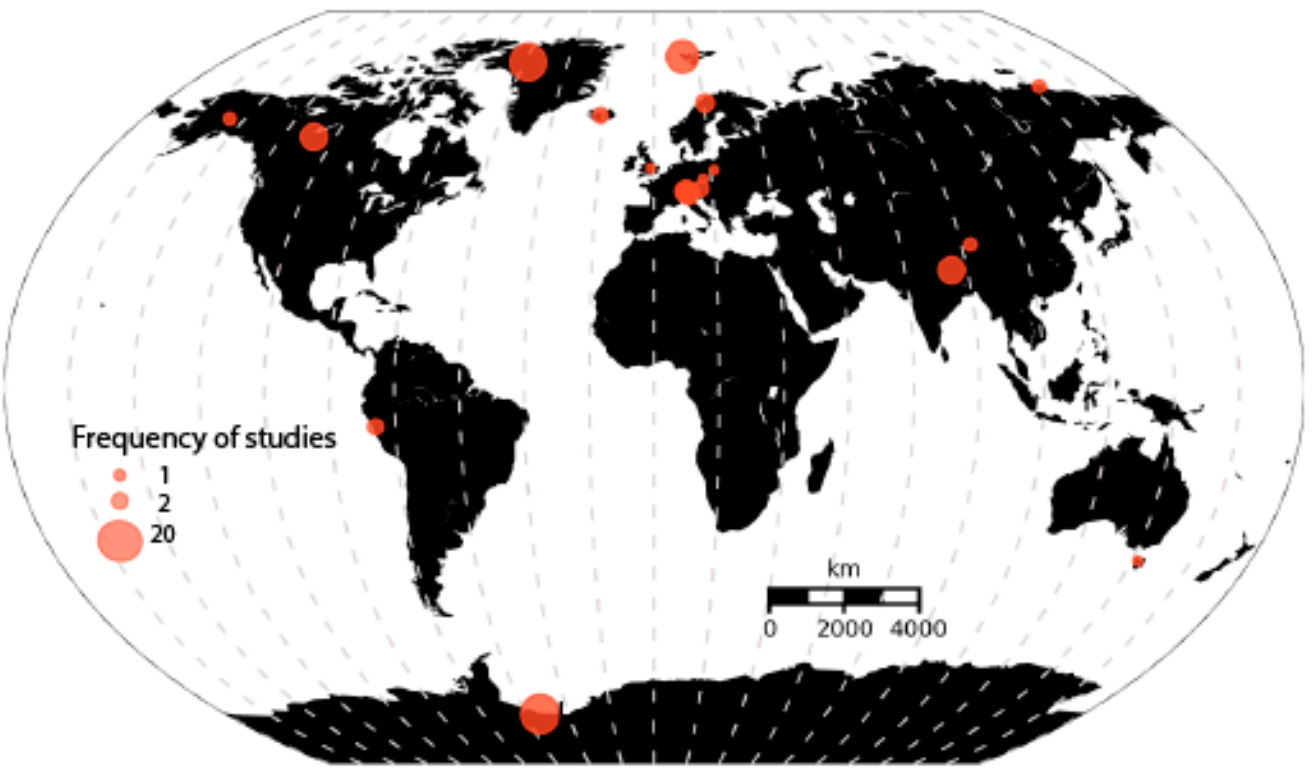

Figure 2. Global distribution of the reviewed study sites. The point size indicates the relative number of UAV flights completed within the peer-reviewed journals, conference proceedings, and university degree theses published online between 2014 and 2019.

\subsection{UAVs for Snow Research}

Several studies utilized UAVs for analyzing snow depth (e.g., $[16,19,34,93])$. The common method for identifying snow depth is to subtract snow-free DSMs from snow-covered DSMs, once the images were correctly co-registered (e.g., [105]). Exact relative georeferencing between the DSMs is essential 
because even small shifts in $\mathrm{x}$ and $\mathrm{y}$ can lead to large differences in the $\mathrm{z}$ direction, especially for steep terrain [28,34]. However, terrain relief and shadows in mountains can put significant constraint on accurate DSM construction and co-registrations. Snow is challenging for building products from Structure from Motion (SfM) algorithms because of the high reflectance of homogenous surfaces and lack of contrast. True to photogrammetric theory, limited variation in surface features could hinder SfM software in identifying tie points to match between images, leading to increased inaccuracy or failure to utilize images within an orthomosaic [94]. Because of this, Bühler et al. [34] suggested fresh snow to be less suitable than older, weathered snow for reliable photogrammetry. They concluded this is less of a problem for alpine surfaces where winds and variation in radiation of snow surfaces develop detectable features such as ripples. However, if the mapping area is of considerable dimensions and navigable, one solution to this problem can be the placement of well-distributed ground control point (GCP) markers as common reference points or tie points for enforcing the SfM. These markers can also ensure common georectification during the process of generating temporal DSMs and enable robust co-registration to make DSMs mutually comparable for accurate differencing. Moreover, the snow albedo during the transition period between winter and summer changes rapidly and even the older, weathered snow cannot be sufficiently reliable to ensure high accuracy for repeat photogrammetry. Shadows or areas of insufficient illumination will also introduce errors in DSMs. To alleviate some of these challenges, having a snow-free image to use as a control is very useful for snow assessment.

With respect to testing SfM performance in varying topographic and lighting conditions for different snow types using low-cost UAVs, Cimoli et al. [16] performed a more holistic approach in Svalbard and Greenland. Of the resulting snow depth maps with spatial resolutions between 0.06 and $0.09 \mathrm{~m}$, the average difference between the UAV-estimated and conventional snow probing depths varied within an acceptable range of 0.015 to $0.16 \mathrm{~m}$. To alleviate the abovementioned issues with homogenous surfaces and lack of contrast limiting SfM applicability for snow, Cimoli et al. [16] demonstrated the potential to overcome SfM limitations through definite image pre-processing workflows. The two pre-processing steps suggested and tested by Cimoli et al. [16] were image content enhancement (increases the contrast between the pixels without reducing the dynamic range) and radial lens distortion correction (improves the image geometry for SfM processing). Another way to overcome the SfM-related limitations in snow depth mapping can be to opt for different sensing approaches. For example, Tan et al. [76] used an experimental airborne radar operating at frequencies between $1.0 \mathrm{GHz}$ to $5.0 \mathrm{GHz}$ to estimate snow depth over Antarctic sea-ice. The radar was capable of performing snow depth measurements at a minimum resolvable layer resolution of $5 \mathrm{~cm}$. However, such a technique requires precise understanding of the snow's physical parameters and their variability in a radargram. Similarly, one of the results obtained by Adams et al. [83] while performing slope-scale snow depth measurements was particularly interesting. In addition to visible spectrum, they acquired images in near-infrared (NIR) wavelengths as well to generate DSMs. They reported that for poorly illuminated snow surfaces, the NIR imagery provided considerably better accuracy than the visible imagery. This result is promising in proposing multispectral imagery in infrared wavelengths for depth mapping as another option to explore for future studies.

The studies on UAV-based snow research found meaningful information on snow depth and distribution, but with some conditions. For example, De Michele et al. [19] found their UAV (ground sample distance (GSD) of $4.5 \mathrm{~cm}$ ) and manual measurement of snow depth differed by $7.3 \mathrm{~cm}$ on average, with a standard deviation of $12.8 \mathrm{~cm}$ and precision of $\sim 10 \mathrm{~cm}$. Though such a precision is a considerable improvement over the satellite-based observations, room exists for improvement to serve as inputs within glacio-hydrological models to produce reliable predictions. De Michele et al. [19] further evaluated snow depth volume in the field by using classical interpolation techniques (specifically arithmetic mean, inverse distance weighting, Thiessen method and Kriging) of point values for 12 poles measuring depth. The field approach greatly underestimated snow volume estimated by the UAV, with the average difference being $21 \%$. The authors attributed some of this error to the placement of measurement poles in locations with shallow snow which should be investigated with increased sample 
points in respect to variations in snow depth and surface texture. In a separate study, Harder et al. [28] concluded that their SfM snow depth and spatial variability estimations were accurate only for areas with snow deeper than $30 \mathrm{~cm}$. Snow shallower than this threshold provided a signal that was smaller than the noise and factors such as vegetation cover, low sun angles, topographic or cloud shadows, and high wind speeds contributed significantly to higher noise. Short vegetation compressed by snow can result in underestimation of snow depth due to elevation bias and conversely, vegetation extending above the snowpack can result in overestimates of snow depth [111]. Maintaining a fine ground sampling resolution that can sufficiently distinguish the intersection of snow and vegetation can help alleviate errors [94].

In another study, Avanzi et al. [92] compared UAV-derived photogrammetric maps, flown at $60 \mathrm{~m}$ for a GSD of $\sim 0.02 \mathrm{~m}$, of snow depth for a flat sample plot with point clouds acquired with a light amplification by th use of a stimulated emission of radiation (laser) device capable of millimetric accuracy. While a conventional laser scanner reflects the laser beam on the target scene using a mirror, the MultiStation laser scanner used by Avanzi et al. [92] acquires a point cloud by moving the telescope collimation axis to scan the target scene at a very high frequency, thus ensuring a high accuracy of $2 \mathrm{~mm}$. Although the two methods of snow depth estimation were in close agreement with the maximum root mean square deviation (RMSD) of only $0.036 \mathrm{~m}$, the root mean square error (RMSE) between UAV data and manual probing reached up to $0.20-0.30 \mathrm{~m}$. This error was more evident in riverbeds and regions with vegetation cover. This highlights the fact that although the recent software and hardware advances have made the photogrammetric results comparable with laser-based measurements, there is still a significant scope of improvement in the accuracy of all such remote-device-based snow depth measurements. The study area selected by Avanzi et al. [92] displayed homogeneous topography within a range of $\sim 7 \mathrm{~m}$. Nevertheless, the accuracy issues related to topographic shadows as suggested by Harder et al. [28] may further aggravate the RMSD between the laser-based and photogrammetry-derived measurements in a topographically heterogeneous region. Devices such as MS are not as affected by sudden topographic variation and can outmatch the results of UAV photogrammetry in the regions with widely heterogeneous terrain. However, for applications that do not require mm-scale precision and accuracy but are mainly constrained by the time factor and need results in near real-time, the methods and recommendations suggested by Miziński and Niedzielski [40] can prove to be useful. They proposed a fully automated two-stage registration method for dense point clouds based on tall land cover elements such as trees without a need for ground control points (GCP) acquisition. The mean absolute error of snow depth estimation reported by Miziński and Niedzielski [40] varied between 0.33 and $0.43 \mathrm{~m}$ among two sample flights at

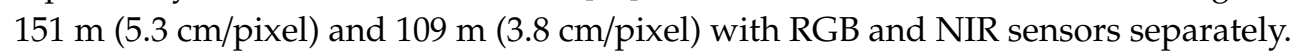

\subsection{UAVs for Glaciology}

Despite challenges associated with flying in high elevations and rarer atmosphere, worldwide UAVs are becoming increasingly popular for mapping alpine glaciers. Several of the compiled studies (e.g., [59,62,112]) focused on utilizing SfM to analyze glacier dynamics. Specific applications included monitoring plume dynamics [73], ablation [98,99], flow velocity [66], and calving events [47,58]. Others include identifying and analyzing changes of surface features such as ice cliffs [13,22,32], cryoconite holes on ice sheets [97], and supraglacial ponds on debris-covered glaciers (e.g., [30]), testing the accuracy of DSMs with varying GCPs (e.g., [60]), and mapping hazards related to glacier collapse and glacial thinning rates (e.g., [63]). Of these, one of the most interesting studies was done by Jouvet et al. [73]. They took advantage of the temporal resolution UAVs can provide, flying over the terminus of Greenland's Bowdoin Glacier every twelve hours (with two exceptions) between July $7^{\text {th }}$ and July $18^{\text {th }} 2016$, totaling 24 flights at $400 \mathrm{~m}$ above ground level, achieving $10 \mathrm{~cm}$ GSD. Also included in their study was a fixed Differential Global Positioning System (DGPS) on the glacial surface. The DSMs comparisons between each flight provided a high-resolution velocity field, and between the two technologies, achieved accurate orthomosaics within 10-20 cm (1-2 pixels) horizontal error. 
Rossini et al. [86] flew an off-the-shelf DJI Phantom 4 quadcopter to analyze the ablation region of Swiss Morteratch Glacier within two summer flights. Though the study utilized a low-cost consumer UAV with a pre-installed camera and only visited their study site twice, their usage of a master and two rover Global Navigation Satellite System (GNSS) devices in the field allowed them to create orthomosaics and DSMs reliable within reasonable error; the upper error limit being $23.3 \mathrm{~cm}$ for the DSM and total RMSE between the orthomosaic and ground validation points of $17.7 \mathrm{~cm}$ produced from a flight altitude $110 \mathrm{~m}$ above ground level and $4.5 \mathrm{~cm} /$ pixel. Specific challenges were met within this study such as chaotic movement from fallen boulders along a glacier's edge and intense changes due to the ablation-disabled SfM algorithm from identifying features between data collection days. These factors reportedly hampered the possibility of proper estimation of the glacial displacement between the July and September dates. A suggestion to relieve the impact of a rapidly changing environment would be to increase the temporal resolution of observations, so dramatic ablation changes in particular, can be witnessed in smaller steps. Outside of the set-backs, with the finished products, Rossini et al. [86] derived surface velocity, brightness, roughness, identified glacial features, and differenced the DSMs from the two dates for a vertical accuracy assessment from stable features as well to quantify surface melt. Furthermore, Rossini et al. [86] showed usefulness of the generated brightness image and roughness map when they analyzed the melt rates with respect to the surface brightness or its roughness. This is an example of effectively using orthomosaics or DSM derivatives for next-level analyses following DSM generation and differencing.

In a study done by Rohner et al. [104], a SenseFly eBee with an RGB camera flown in four day increments was able to capture velocity flows of a marine-terminating glacier in Greenland. Compared to satellite-derived velocity fields, the UAV was able to depict much smoother flows and resolve the acceleration towards the terminus, where speeds of $12 \mathrm{~m} /$ day were reached. The higher resolution (both in space and time) also distinguished discontinuities in flow speed related to deep crevasses and rifts that would be indiscernible with satellite imagery. The study also compared velocity fields produced by terrestrial radar interferometer and found excellent agreement between the two very different sensors with the exclusion of a $250 \mathrm{~m}$ buffer from the margins of the glacier (standard deviation of $1.84 \mathrm{~m} /$ day and mean difference of $0.37 \mathrm{~m} /$ day with UAV GSD $\sim 17 \mathrm{~cm}$ ). The position of the UAV had an advantage over the terrestrial method as the latter produced discontinuous results due to topographic-induced shadows. Rohner et al. [104] considered the UAV data as in situ truth to validate satellite estimations, demonstrating a shift in the literature from a narrative of if UAVs can be useful or accurate, to assuming so.

In pursuit of estimating debris thickness on glaciers by their thermal signatures, Kraaijenbrink et al. [87] flew both an optical and thermal sensor over a section of Lirung Glacier in Langtang Valley to identify ground objects and validate radiometric values with a hand-held forward-looking infrared (FLIR) sensor. Challenges of flying thermal were the increased energy consumption of the sensor, which decreased the potential UAV flight time, and rapidly changing surface temperature conditions, which impede the feasibility of performing multiple flights. Within single flights, changing conditions caused disagreements between the UAV and in situ measurements with the FLIR. The viewing angle difference among sensors also caused discrepancies. Therefore, extra effort should be given to details such as data collection timing when using infrared. The authors suggest capturing ground-based thermal video rather than images to ease syncing. Additionally, nadir-rigging in situ FLIR can alleviate multisensory comparisons.

\subsection{UAVs for Other Polar Applications}

UAVs have been increasingly utilized for applications such as vegetation, landforms and animal research. The ecological studies ranged from mapping indigenous fauna in Antarctica to an opportunistic examination of polar bears (e.g., [85]). UAVs were useful for identifying mass and body conditions of pinnipeds (e.g., [10,55]), estimating populations of seabirds and pinnipeds including distinguishing demographics such as pups versus adults (e.g., [4]), and behavioral observations both in 
non-invasive settings and conversely using the UAV as a disturbance to measure reaction (e.g., [44,64]). Weimerskirch et al. [64] found that flying UAVs above a threshold height of $50 \mathrm{~m}$ near colonies is preferable as the impacts on their eleven penguin species sampled were negligible. This altitude is not limiting of high-resolution ecological research such as mapping, behavioral studies, and monitoring populations, and most of the commercially available rotary wing drones are equipped with the cameras capable of providing $\sim 2 \mathrm{~cm} /$ pixel resolution images from these altitudes.

Typically, UAV flights are conducted by keeping the UAV within constant direct view of the pilot. Risks of losing or crashing the UAV increase if operated outside the field of view. However, using a UAV for a Beyond Line of Sight (BVLOS) survey, Zmarz et al. [4] were able to perform a more holistic analyses comprising of wildlife, vegetation, and landforms. Flying BVLOS allowed researchers to overcome one of the limitations of UAVs of having to launch and land close to the study site, but BVLOS is commonly discouraged and even illegal in major areas, including North America. The Korczak-Abshire et al. [93] study used the same flight as that in Zmarz et al. [4] to analyze seabird and pinniped populations at Turret Point and Penguin Island, $30 \mathrm{~km}$ away from their site near Henryk Arctowski Polish Antarctic Station. The mission covered a total distance of $230 \mathrm{~km}$ within 2.25 hours. The study promotes UAVs for census work of Antarctic seabirds and pinnipeds and called for automatic estimation techniques to be developed to increase efficiency and accuracy of such analysis as the authors counted individuals manually. Though the populations were counted three separate times, this leaves comfortable room for human error, creating a desire for a machine learning process to be attempted in future studies. In one novel study, Cook et al. [109] applied a random forest supervised classification using directional reflectance measurements as training data to a low-flown (30 $\mathrm{m}$ above ground) multispectral orthomosaic to map algae on the Greenland ice sheet. Combined with additional satellite and in situ measurements, they documented the positive albedo feedback effect contributed by surface algae in Western Greenland (responsible for $6 \%-9 \%$ of total runoff from the western sector in summer 2016). In this case, the UAV survey was critical in distinguishing the effect of algae cells to that of mineral dust on the ice surface and confirming algal blooms are a major component of the ice surface. This study illustrates how UAV imagery in conjunction with other remote sensing and field methods can provide deeper insight than traditional methods.

Antarctic vegetation, specifically cyanobacterial mats, were a popular study subject (e.g., [7-9,56]. In the study by Turner et al. [8], a visible camera, multispectral camera, and thermal infrared camera were flown individually onboard a multirotor by a Mikrokopter "Oktokopter" for investigating moss ecosystems. This is a great utilization of the platform, although the authors describe the Oktokopter as only having a flight duration of $5 \mathrm{~min}$ when carrying the typical payload. The study did not elaborate further, but that is a challenging constraint and greatly limits suitable survey area.

Similar to the identification of features on glacier surfaces, periglacial landform features were also distinguished from the mapped products. Dabski et al. [57] utilized a fixed-wing aircraft to vectorize periglacial landforms on their survey of Demay Point on King George Island in the Western Antarctic Peninsula region. Specifically, they inventoried solifluction landforms, patterned ground, coastal landforms landslides, mud flows, scarps, taluses, bedrock outcrops and more. These landforms can be correlated with the possible presence of permafrost and Dabski et al. [57] provides a methodological sequence in effectively mapping and monitoring them. They concluded that traditional accessible satellite and aerial images underestimate the spatial extent of periglacial landforms and the UAV offered a more competitive level of detail. Mapping permafrost through satellite imaging has always been extremely challenging as the typical permafrost landform patterns such as furrows and ridges in rock glaciers, polygonal forms, and other patterned grounds are hard to distinguish on coarser than a few meters resolution images and UAV imaging can provide unprecedented details for such visual analyses. Surprisingly, few studies currently exist in this realm. Lousada et al. [65] used drone imagery for mapping ice-wedge networks and found that these systems could only be analyzed adequately with $20 \mathrm{~cm} /$ pixel imagery or finer, eliminating the usability of satellites. Another permafrost application by Gonzalez, et al. [77] used UAVs to create high-resolution DSMs to describe pingo 
(conical ice-cored hill) morphologies, but at the time of writing, this work was not yet published in the final form. Van der Sluijs et al. [91] used various fixed wing and multirotor UAVs with five optical and one thermal sensor to identify thaw slump features using a previous LiDAR survey as a baseline. Additionally, they were able to collect high-resolution soil stratification images along a headwall, which would have been a hazardous task to sample otherwise. Through repeated surveys, they were able to quantify the annual volume of displaced material due to melt processes. The thermal imagery described terrain characteristics and processes of slump development, complimenting the high-resolution DSMs (horizontal accuracies 0.6-1.2 GSD RMSE, vertical accuracies 0.6-3 GSD RMSE) that were standardized to $0.5 \mathrm{~m}$ resolution for effective comparison between the various optical sensors used. Authors noted permafrost dynamics such as injection ice and terrain uplift were difficult to detect prior to the use of UAVs. The study provides an excellent example of how several platforms, including off-the-shelf UAVs can be used and reliably compared for assessing permafrost stability that threaten human infrastructure.

Burkhart et al. [51] flew a fixed-wing Cryowing in Greenland to validate Moderate Resolution Imaging Spectroradiometer (MODIS) albedo products for the extent of one pixel. The UAV was fitted with upward- and downward-facing hyperspectral radiometers to calculate albedo. Tilt corrections of the upwards-facing sensor were applied post-flight because effects caused by roll and yaw angles on the measurements vary with solar zenith angle, surface albedo, sky conditions, and wavelength. Further corrections had to be made to offset sensor disorientation due to dismounting and remounting for maintenance, or from the thrust of the catapult at launch. Prior to data analysis, the Burkhart et al. [51] study also utilized radiance and irradiance spectra simulations for noon for their site multiplied with MODIS bands 1, 3, and 4 response functions, and then integrated this with the UAV nadir measurements to the corresponding narrow bandwidths in an attempt to correct for atmospheric effects. The result showed a less than $0.2 \%$ change in the bands between the sensor and the surface reflectance and, therefore, the uncorrected data were used. However, a point in their conclusion was that even for low-elevation flights, reflectance measurements may be influenced by haze. A suggested remedy for this is to include aerosol observations to correct surface reflectance [51]. Correction for atmospheric effects for low-flying UAV surveys is a processing step that is often bypassed in UAV surveys but discounting it can dampen contrast within images [113]. A clear, standard methodology for correcting alpine environments' atmospheric variation for UAVs in particular is currently lacking and further investigation on the topic is encouraged.

\section{Hardware, Software, and Regulations}

\subsection{UAVS}

Figure 3 addresses flying mechanism (multirotor or fixed-wing platform), while Figure 4 characterizes the categories on the basis of the commercial brand used. Of the application studies surveyed, $60 \%$ utilized a multirotor, $39 \%$ fixed-wing and 1\% (representing one study) used a hybrid of the two. The possible reasons for the popularity of the multirotors are that they are relatively less expensive, they often have dimensions which are reasonable for handling and transportation, and have relatively safer launch and landing procedures to operate in extreme environments. The most popular multirotor brand in our literature survey was DJI [114], followed by custom-built and various research-specific platforms. DJI is the most popular brand of UAV in the U.S. and have some of the most advanced yet affordable communication equipment available within a black-box set up. The DJI OcuSync Air System offers high-resolution video transmission that has a larger range than analog and can quickly re-establish lost connection with its Cross-Layer Protocol Design [115]. Custom-built multirotors assembled using various manufactured parts were found to be surprisingly popular. Though greater risk can be involved with building UAVs from scratch, this allows greater control of the design and more specific applications. For a study on Llaca Glacier in Peru, Wigmore and Mark [2] built a multirotor capable of maintaining flight up to $6000 \mathrm{~m}$ ASL. The decreased air density at higher 
elevations significantly reduce lift produced by propellers. To get around this, the UAV was built with longer arms and propellers to maximize surface. These were supported by high-speed motors to lift the all-around lightweight carbon fiber body. Their specific design was capable of flying for $25 \mathrm{~min}$ at sea level, but this duration is halved at $5000 \mathrm{~m}$ ASL. The experience of decreased battery life at high altitudes was commonly shared (e.g., [16]). Though fixed-wing platforms offer a much longer flight duration, the benefits of increased flight control, decreased need for a smooth landing area, and resilience in variable wind provided by the multirotor were prioritized [2].
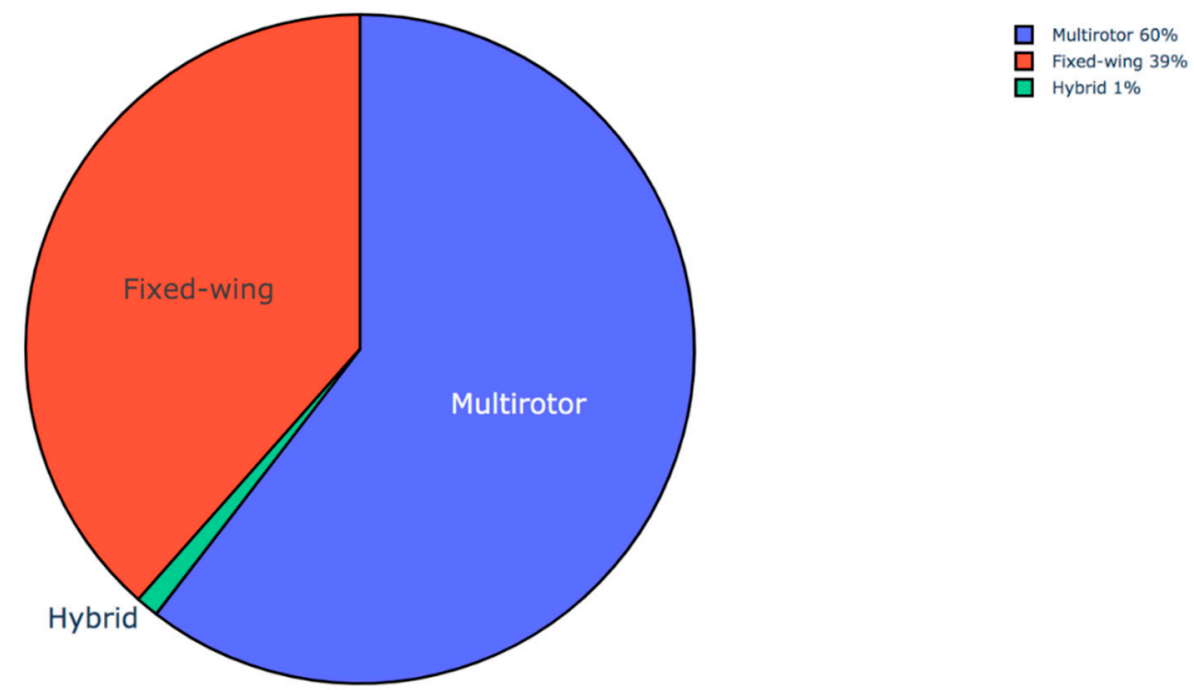

Figure 3. The UAV hardware technology used by the studies. Percentages indicate the frequency of use surveyed from the studies. All platforms were included for studies that employed multiple UAV types.
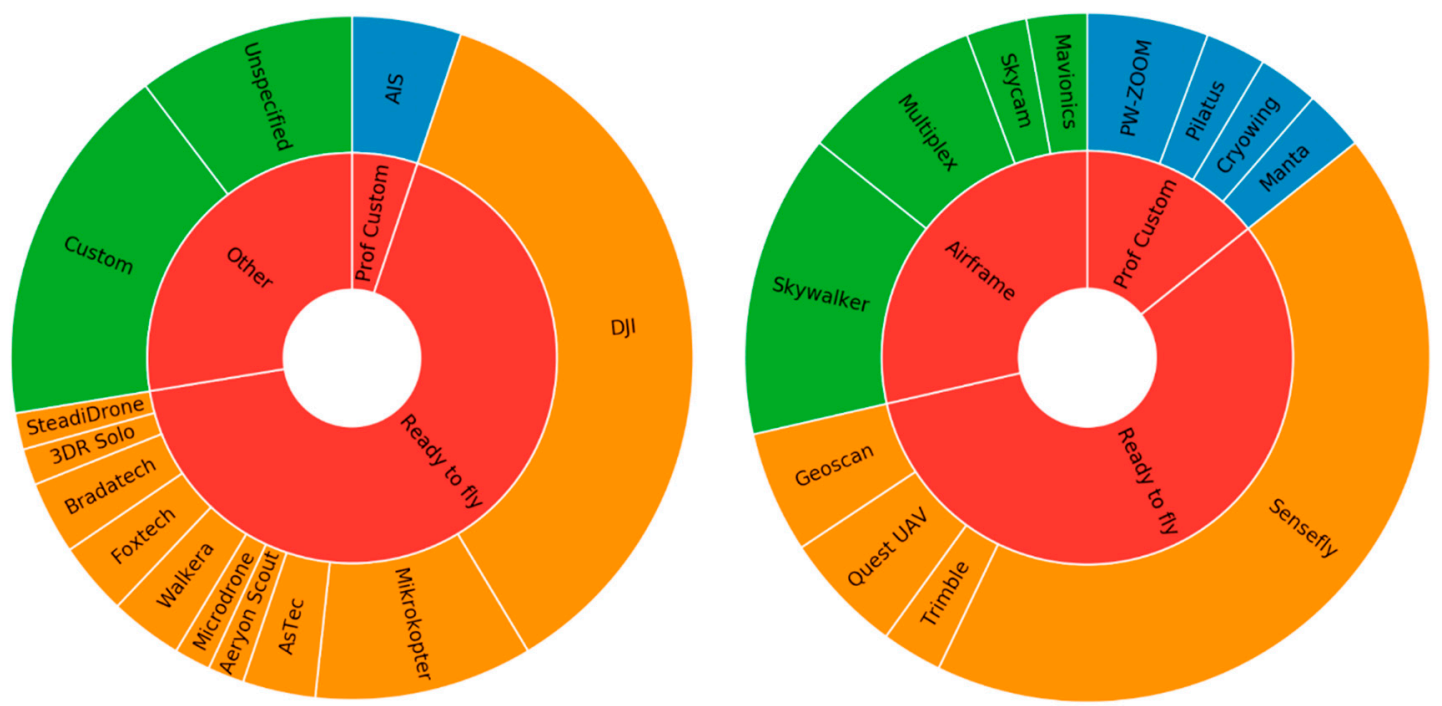

Figure 4. The preferred brands of multirotor (left) and fixed-wing (right) vehicles used among the surveyed studies. Inner circles of each categorize the chosen platforms as ready to fly/off the shelf UAVs, if they were an airframe that requires some customization, or professionally customized UAVs. Note multirotor "AIS" is an abbreviation for Aerial Imaging Solutions. Multirotor category "Custom" includes studies that explicitly said they flew a customized multirotor. The sample size for multirotor and fixed wing brands was 58 and 35 respectively.

Of the fixed-wing studies, the ready-to-fly Sensefly eBee was the most popular model, with the Sensefly SwingletCAM and the customizable Skywalker following (Figure 4). The PW-ZOOM UAV used by Dabski et al. [57], Korczak-Abshire et al. [93], and Zmarz et al. [4] was a fixed-wing that 
allowed for the demand of 1 to 3 hour long missions to survey a target that was a few dozen kilometers away from the launch site. The PW-ZOOM fixed-wing required a launcher for take-off and about $50 \mathrm{~m}$ of free space to land. Certain adjustments were made to adapt the UAV to a harsh landing in diverse terrain conditions and to withstand operations in low temperatures. Specifically, the carburetor of the engine and the Pitot tube (i.e., airspeed sensor) had deicing protection and the front of the fuselage was strengthened. The Sensefly eBee used in Bollard-Breen et al. [9] also had impact protection on the fuselage and wings, and also bright livery added to enhance visibility. Outside of protection from rough terrain and being visually lost, all of the avionics were "off the shelf" and no specific cold-weather-rated electronics were necessary for their January flights in the McMurdo Dry valleys of Antarctica. It is not entirely clear if these precautions are necessary. In an interview, certain UAV industry experts have stated icing is only a risk between temperatures of -5 and $4^{\circ} \mathrm{C}$ with added humidity [49]. Therefore, manipulations to UAV platforms may be extraneous depending on environmental conditions.

So which platform is better? Though the goal of specific missions may make this answer obvious, in situations where either platform is viable (for example surveys of $\sim 100 \mathrm{~m}^{2}$ flat areas) multiple factors should be carefully weighed. Papers that described a preference of a multirotor vehicle over fixed-wing attributed this to portability, limited sound (quiet), ability to take off and land from a confined area, larger payload capacity, wind resistance, and increased stability [2,10,19,34]. Conversely, as pointed out in Harder et al. [28], there has not yet been any direct comparison studies of products derived from multirotors and fixed-wing that could validate the stability claim, nor that fixed-wings have a higher wind resistance than multirotors (over $14 \mathrm{~m}$ per second, though image quality becomes inconsistent at this level). Other papers also stated that because their fixed-wing UAV could fly faster, they are more resistant to strong, unpredictable Antarctic winds (up to $23 \mathrm{~m}$ per second) [4,57,93]. The limited battery autonomy due to the lack of aerodynamic lift in high elevated areas of typical multirotors was a deterrent for some [52]. The Bühler et al. [34] study was the only one that utilized both forms. It noted the clear disadvantages of multirotors such as the limited 6-10 min of flight time above $2000 \mathrm{~m}$ ASL, and therefore, there is a need for take-off and landing to be close to the study site, which is not always possible. However, they found the multirotor acquired high quality even in $20 \mathrm{~m}$ per second gusts, while the fixed-wing was more sensitive. Clearly there is not a consensus on which is more wind-tolerable among the cryosphere researchers, but at this time, the comparison by Bühler seems to be the most reliable.

An interesting addition to the survey was the hybrid system used by Jouvet et al. [73]. The Firefly6 features a fixed-wing frame but with rotors in the front and back, which lends it the ability to land and take off vertically. This gives it the benefit of landing in a confined area while also having the range similar to that of a fixed-wing. Still, this sort of hybrid system is most appropriate for monitoring areas smaller than $10 \mathrm{~km}^{2}$ [116]. The disadvantage of the hybrid is that it is more sensitive to gusts of wind while in hover mode. However, we expect that these will have an increasing presence in the upcoming research applications.

\subsection{Sensors}

While UAVs, especially multirotors, are capable of carrying many sensors, a few of the papers had specific comments on the visible sensors that they chose. The majority of the studies used RGB sensors, with the most popular being Sony NEX, Canon IXUS, and Canon Powershot series (Figure 5). Goebel et al. [10] included a comparison of three mirrorless digital cameras in addition to their Antarctic penguin study: a Sony NEX-5, Canon EOS-M, and an Olympus E-P1. While all the cameras performed well, the Olympus was the favorite because the number of available lenses and the analogue video output that could be transmitted to the ground station. To reduce the weight of the sensor, they removed the housing, LCD screen, and battery to alternatively hard-wire to the UAV power. The remaining camera, fitted with a $45 \mathrm{~mm}$ lens flown at $45 \mathrm{~m}$ provided $1 \mathrm{~cm} /$ pixel resolution [10]. Considerations when selecting RGB cameras should include a quality lens to reduce geometric distortions, and less obvious, the charge-coupled device that could influence the signal-to-noise ratio of 
collected data [117]. Van der Sluijs et al. [91], when mapping permafrost thaw features, suggested using a standard minimum size and resolution of greater than or equal to 1 inch sensor and 16-20 megapixels, respectively, to ensure precision and accuracy of DSMs. This protocol proved to be useful for a range of flight altitudes 40-120 m above ground. Lastly, several studies used the preinstalled camera from off-the-shelf DJI products. While these served many applications well, van der Sluijs et al. [91] found the Zenmuse X5 camera onboard the DJI Inspire 1 Pro had a relatively slow-rolling shutter, producing motion distortions that had to be corrected post-flight. Increasing shutter speeds while balancing other exposure parameters such as ISO and lens aperture can improve blurred distortions [118], although specific calibrations vary with sensor, illumination, and flight plan.
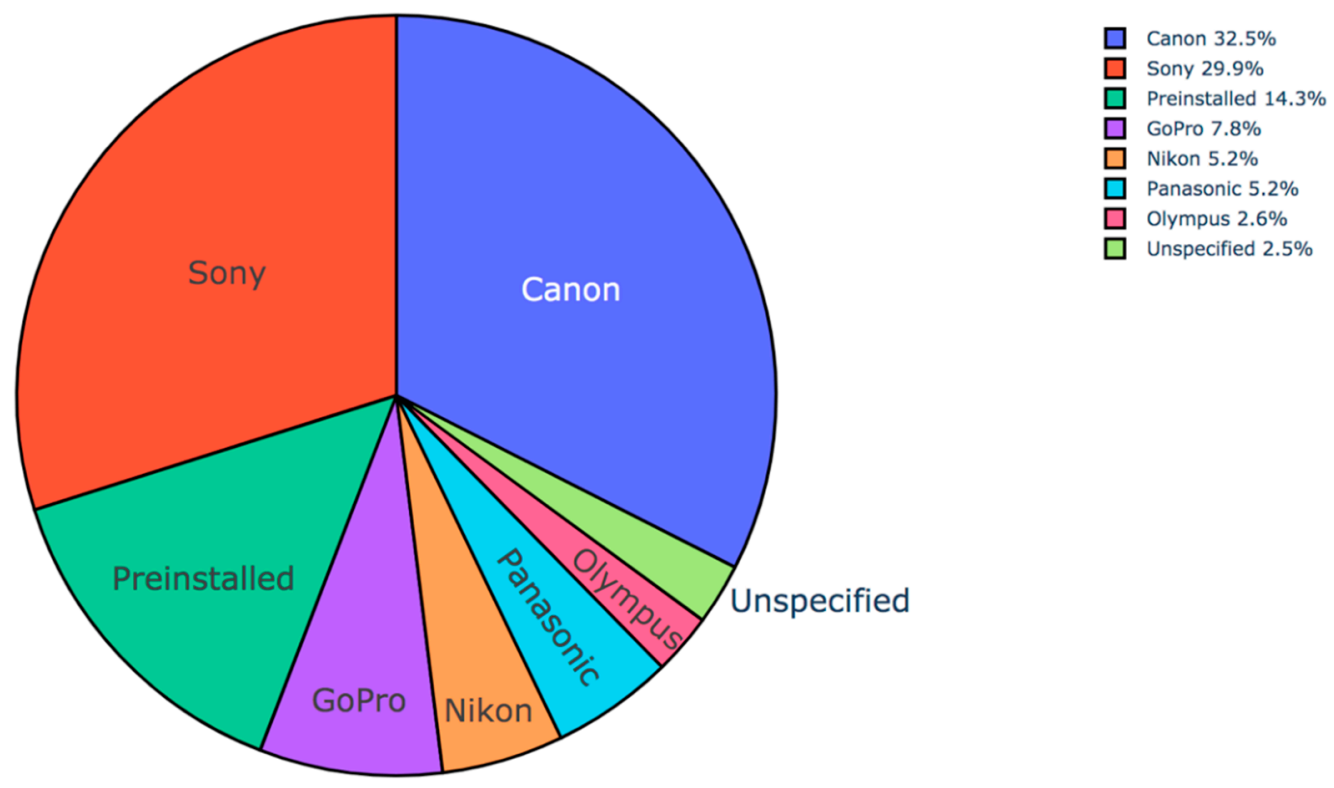

Figure 5. Digital camera brands for RGB collection used by the reviewed studies with percentages representing the proportion of studies utilizing each brand.

In addition to the popular RGB imagers, here we suggest several new and emerging camera systems which are UAV-mountable and capable of covering entire visible, NIR, short-wave infrared (SWIR), and thermal wavelengths in hyperspectral resolutions (e.g., $[51,56,76,84,101])$. The miniaturization of LiDAR has encouraged its uptake as an added capability to UAV surveys [11,119]. These technologies hold immense potential for unravelling the cryospheric dynamics. For example, in addition to enabling thermal imaging and monitoring of glaciers and periglacial landforms during night or polar nights, the use of hyperspectral sensors in UAVs can help develop spectral libraries for precisely mapping different types of snow and glacier facies, debris cover, and extents of black carbon depositions. Such images can also aid geological and lithological mapping of the surrounding cliffs and plains and if studied in conjunction with the melt-water chemistry of the glaciated catchment, such lithological information can be very useful in estimating the differential weathering of various rock types due to ongoing glacio-fluvial erosions. The results can have implications for ensuring sustainability of hydropower plants in high mountains.

UAV-borne hyperspectral sensors covering visible to SWIR wavelengths are yet to reach a similar level of popularity in usage as that of RGB and thermal sensors for glaciological research. This is primarily due to their expensive costs. However, miniaturizing hyperspectral sensors is another challenge and common hyperspectral sensors are heavy, especially those that incorporate full visible and SWIR spectral ranges. Nonetheless, the technology is rapidly evolving and the usability of hyperspectral sensors for UAV-enabled research is expanding (e.g., [120]). For example, Malenovský et al. [56] flew a Micro-Hyperspec (Headwall Photonics, Inc., Fitchburg, MA, USA) onboard an octocopter to monitor Antarctic vegetation. Micro-Hyperspec sensors weigh $0.7-2.0 \mathrm{~kg}$ 
excluding lens, depending on the sensor's spectral range [121]. The application was convenient in this case because the sensor was flown only $11 \mathrm{~m}$ above ground level, reducing the need for increased battery drain required for higher altitude flights, which could instead be dedicated to the increased payload. However, UAV-flown hyperspectral have been used in several vegetation and mining applications that include slightly higher altitude flights. A few examples are Jackisch et al. [122], who flew a $720 \mathrm{~g}$ Rikola hyperspectral camera (Senop Oy, Kangasala, Finland) at $50 \mathrm{~m}$ on an Aibot X6 V2 hexacopter and Arroyo-Mora et al. [123], who flew a $2760 \mathrm{~g}$ Compact Airborne Spectrographic Imager (ITRES Research Ltd., Calgary, AB, Canada) on a DJI Matrice 600 Pro at their maximum altitude of $60 \mathrm{~m}$ above ground level. Still, such sensors can help develop precise spectral libraries for different types of snow and glacier terrain, further assisting in their effective characterization and in developing automated classification routines for glacier mapping.

\subsection{Software}

The majority of the papers (57) used Agisoft [124] for their SfM products, with Pix4D [125] as the runner-up (15), and MicMac [126] and Adobe Photoshop [127] each occasionally utilized (Figure 6). Bernard et al. [52] created orthomosaics and DSMs of a glacial basin from both MicMac and Agisoft to compare. Although the general trend of the geometry between the othophotos were consistent, there were discrepancies of some features that exhibited a shift of $10 \mathrm{~m}(\mathrm{GSD} 5 \mathrm{~cm})$. The authors also experienced a doming of surfaces on the UAV DSMs likely due to faulty lens-modelling distortion; however, further investigation into the large errors is recommended. The DSMs were compared to each other, and the standard deviation along a cross-section of elevation was $0.9 \mathrm{~m}$. Each DSM was then compared to a LiDAR DSM collected at a summit overlooking the field site and the standard deviations between the DSMs to this "control" differenced by only $0.1 \mathrm{~m}$, with the Agisoft yielding the lesser standard deviation of $0.6 \mathrm{~m}$. The authors did not specifically report which software produced a more accurate product. Another comparison by Isacsson [81] used Pix4d and Agisoft to orthomosaic the same survey. Agisoft aligned 142 images and Pix4d aligned only 108 out of the 203 captured images. Comparing self-reported errors, Agisoft had higher errors in the $\mathrm{x}$ and $\mathrm{y}$ position, while Pix $4 \mathrm{~d}$ had higher $z$ error. However, this is the result of just one orthomosaic and is, therefore, not generally representative of the differences in algorithm outputs. Hendrickx et al. [106] reconstructed ten versions of a DSM within Agisoft using the same inputs of a RGB UAV survey of a rock glacier to test variability produced by random elements contained in the proprietary (unpublished) SfM algorithm. Data were collected at a constant $90 \mathrm{~m}$ above ground level, providing a GSD of $1.4 \mathrm{~cm} /$ pixel with $70 \%$ forward overlap and $65 \%-70 \%$ side overlap. They found highest variability (up to $3 \mathrm{~m}$ ) at the edges where overlapping images are limited. Steep slopes produced variation up to $10 \mathrm{~cm}$, though this is within reasonable model accuracy. In a review of the current state-of-the-art on SfM workflows in geomorphometry, Agisoft was found to be, by far, the most popular [128].

Harder et al. [28] used Terra 3D, a previous version of Pix4D, and concluded that the black-box nature of the proprietary software and limited ability to adjust parameters disadvantaged this software from being a useful tool for scientific purposes. Conversely, Mölg and Bolch [129] compared multiple popular SfM software, including Pix4D and Agisoft, and have concluded these are mature enough to be used for scientific glaciological research granted quality GCP coverage and best practices for data collection are followed. Another freely available option, VisualSfM, found in QGIS (also ArcGIS) is capable of producing negligibly lower accuracy than Agisoft Photoscan for DSMs [130]. 


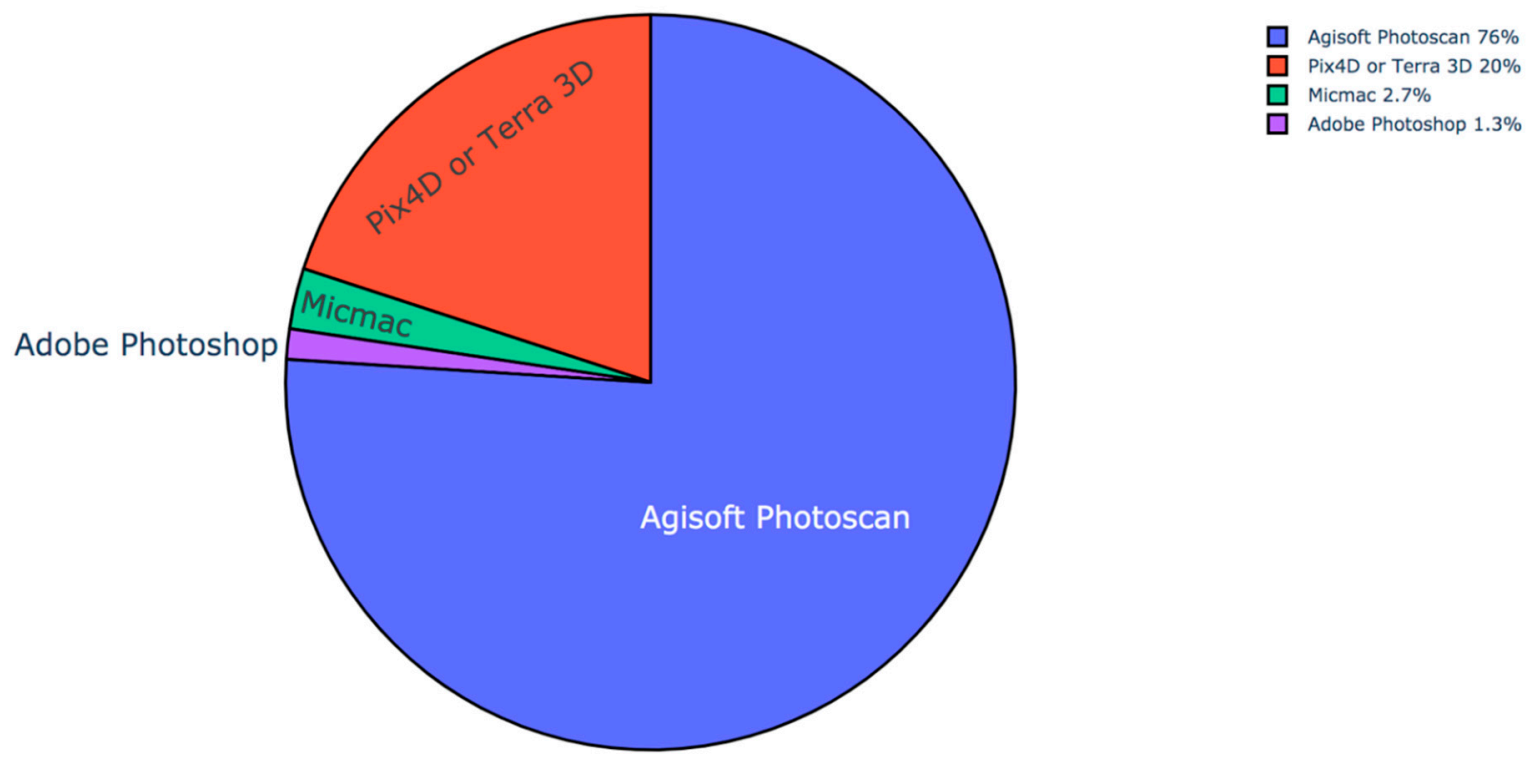

Figure 6. The orthomosaic software used by the studies. Percentages indicate the frequency of use surveyed from the studies.

\subsection{Flying Regulations}

Globally, regulations of UAV surveying have developed rapidly in response to the growing popularity of the technology. Any scientific UAV operation must first consult the legislation regulating UAV operations in the intended location [131]. Understandably, regulations range per country and even the absence of formal restrictions still require communication with local authorities. A lived example of this was field work that occurred on Ascension Island, which at the time, did not have regulations, yet the pilots needed to submit identification and flight plans months in advance to local authorities [131]. Still, even in areas where UAV flights are generally barred, there are opportunities to acquire permissions. In Antarctica, a pre-agreed and precise chain of communication made the surveys of delicate cyanobacterial mats possible [9]. Even for missions within non-restricted airspace, it is expected that UAV pilots obtain a Remote Pilot Certificate that will need to be renewed every two years (U.S.). In fact, in most relevant areas, some sort of pilot certification is increasingly becoming a requirement. For example, beginning June 2019, this became effective in Canada, which now offers multiple certifications depending on protocols for basic or advanced flights. Most of the countries holding the study sites of the UAV papers researched have protocol for obtaining licenses. Antarctica, Greenland and Iceland do not list explicit expectation for pilot certification, though each still have several rules and expectations of acquiring permits for defined cases. Many countries have similar rules for flying, such as to not exceed $122 \mathrm{~m}$ altitude above ground level, requiring the drone to be always within line of sight of the pilot, and registration of UAVs with the respective authority along with clear labeling on the drone itself. Permissions to perform outside of the general rules might be obtained by applying in advanced of the mission, as is necessary in the BVLOS missions previously mentioned. There are several websites that offer bullet-points of rules per country (e.g., [132,133]) and many countries have databases such as USA's Notices to Airmen (NOTAMs) that include essential information on airspace restrictions. It is best practice to indicate intent on UAV flights to other users of airspace including regional civilian and military air traffic control, or direct users such as local charter flight companies if traffic control is nonexistent, which is possible in remote areas [131]. However, rules and regulations around UAVs are constantly evolving, so researching the jurisdiction of study areas is crucial during the early stages of mission planning. The International Civil Aviation Authority offer a UAS Toolkit to direct viewers to the relevant authority for each country [134]. For more resources detailing current global regulations, we recommend Stöcker et al. [135]. 


\section{Discussion and Recommendations}

The breadth of cryospheric elements that could be better analyzed using UAVs has been demonstrated within the 103 studies that have been reviewed here. However, there is still plenty of room for growth in this general field of research. Suggestions for future applications of UAVs are listed in Table 2.

Despite the target of the intended study, many considerations must be evaluated before a successful UAV mission can take place. The determined priorities regarding sensor, battery life, and area of interest will dictate which kind of UAV will be most appropriate per application, as there is no clear overall preference. Non-technical considerations, such as regulations on flying restrictions beyond line of sight within the US, Canada, or elsewhere will restrict operations. The rules and expectations of applicable authorities should always be addressed when designing a research plan in addition to acquiring all the needed permits. When planning a flight mission, check permitted radio frequencies (e.g., $433 \mathrm{MHz}, 915 \mathrm{MHz}, 2.4 \mathrm{GHz}, 5.8 \mathrm{GHz}$ ) and power settings for radio transmissions as these may vary among jurisdictions [131]. The authors also recommend viewing air navigation charts online prior to arriving to the field and storing these maps within a flight planning software to use if internet connection is unavailable in the field.

Other considerations are necessary for the physical UAV flight. Off-the-shelf multirotor platforms were a popular choice with relatively inexpensive, ready-to-fly DJI UAVs being the most used technology among the reviewed studies. However, because most of such small multirotor UAVs are inexpensive, they are also equipped with poor Global Positioning System (GPS) receivers. In open plains, these GPS receivers have a positional accuracy within $10 \mathrm{~m}$ but in mountainous areas where GPS reception is already weaker, these GPS receivers can perform poorly. This is a huge constraint in following automated flight plans for such UAVs and there is always a possibility of losing the drone due to collision with the surrounding cliffs. Moreover, in the high mountains where the air pressure is low, the multirotor platforms can show some instability and image distortions. UAVs are more susceptible to weather events such as wind gusts and precipitation than manned vehicles. Further, weather influences such as excess wind speeds and cold temperatures compound drainage to batteries. Choice of sensor in terms of increasing payload and energy consumption will also decrease flight time [88].

Table 2. Possible UAV capabilities in key Arctic research topics. Adapted with permission from AMAP's Enabling Science use of UAS for Arctic Environmental Monitoring, Ch. 7 [136].

\begin{tabular}{|c|c|c|c|}
\hline \multicolumn{4}{|c|}{ Key Topics } \\
\hline Lower Atmosphere & $\begin{array}{c}\text { Oceanic and Sea Ice } \\
\text { Processes }\end{array}$ & $\begin{array}{c}\text { Glacier and Ice Cap } \\
\text { Dynamics }\end{array}$ & Ecosystem Resilience \\
\hline Aerosols and Black Carbon & Sea-ice properties & Glacier mass balance & Terrestrial \\
\hline $\begin{array}{l}\text { Optical particle } \\
\text { counters for measuring } \\
\text { aerosol concentration } \\
\text { and size distribution. } \\
\text { - } \quad \text { Filter samplers for } \\
\text { aerosol composition. } \\
\text { - Cloud Condensation } \\
\text { - } \quad \text { Suclei (CCN). } \\
\text { Spectrometers for } \\
\text { measuring aerosol and } \\
\text { surface spectral } \\
\text { radiative properties. }\end{array}$ & $\begin{array}{l}\text { Precision GPS and laser } \\
\text { altimeter for measuring } \\
\text { sea ice thickness } \\
\text { (freeboard) } \\
\text { and roughness. } \\
\text { Ground penetrating } \\
\text { radar (GPR) for } \\
\text { measuring snow on ice. } \\
\text { Camera for } \\
\text { characterizing sea ice } \\
\text { types, concentrations } \\
\text { and melt } \\
\text { pond fractions. } \\
\text { Spectrometers for } \\
\text { sea-ice spectral } \\
\text { albedo measurements. }\end{array}$ & $\begin{array}{l}\text { Laser altimeter or laser } \\
\text { scanner for mapping } \\
\text { surface elevation and } \\
\text { thereby glacier mass } \\
\text { and year to year total } \\
\text { glacier mass changes. } \\
\text { Ground penetrating } \\
\text { radar for facies } \\
\text { characterization and } \\
\text { changes in } \\
\text { accumulation and melt. }\end{array}$ & $\begin{array}{l}\text { - Hyperspectral imagers } \\
\text { with very high } \\
\text { resolution for } \\
\text { vegetation mapping. }\end{array}$ \\
\hline
\end{tabular}


Table 2. Cont.

\begin{tabular}{|c|c|c|c|}
\hline \multicolumn{4}{|c|}{ Key Topics } \\
\hline Lower Atmosphere & $\begin{array}{l}\text { Oceanic and Sea Ice } \\
\text { Processes }\end{array}$ & $\begin{array}{c}\text { Glacier and Ice Cap } \\
\text { Dynamics }\end{array}$ & Ecosystem Resilience \\
\hline Clouds & Ocean properties & Glacier dynamics & Marine \\
\hline $\begin{array}{l}\text { Cloud particle imager } \\
\text { for measuring cloud } \\
\text { particle size and shape } \\
\text { distribution in water, } \\
\text { mixed phase and } \\
\text { ice clouds. } \\
\text { Radiometers for } \\
\text { measuring cloud } \\
\text { radiative properties. }\end{array}$ & $\begin{array}{l}\text { IR thermometer for } \\
\text { measuring sea } \\
\text { surface temperature. } \\
\text { Synthetic aperture } \\
\text { radar (SAR) for } \\
\text { measuring surface } \\
\text { winds and waves. }\end{array}$ & $\begin{array}{l}\text { Camera (visual or } \\
\text { infrared), for } \\
\text { estimating calving rates } \\
\text { and dynamic mass loss } \\
\text { rates compared to mass } \\
\text { loss by melting. } \\
\text { Synthetic aperture } \\
\text { radar (SAR) feature } \\
\text { tracking for estimating } \\
\text { glacier flow velocities. }\end{array}$ & $\begin{array}{l}\text { - Cameras (visual or } \\
\text { infrared) for marine } \\
\text { mammal surveys. }\end{array}$ \\
\hline
\end{tabular}

\begin{tabular}{|c|c|}
\hline Surface energy fluxes & Ocean color \\
\hline $\begin{array}{l}\text { Turbulent flux probes } \\
\text { and radiometers for } \\
\text { measuring } \\
\text { ocean-ice-atmosphere } \\
\text { energy exchange and } \\
\text { characterizing the } \\
\text { effects of leads and } \\
\text { melt ponds. }\end{array}$ & $\begin{array}{l}\text { Imaging spectrometer } \\
\text { for measuring ocean } \\
\text { color to determine } \\
\text { nutrient and } \\
\text { chlorophyll concentrations. }\end{array}$ \\
\hline Meteorology & Energy Transport \\
\hline $\begin{array}{l}\text { - Standard } \\
\text { meteorological pack for } \\
\text { measuring air } \\
\text { temperature, humidity, } \\
\text { wind and air pressure. } \\
\text { Drop sondes for profile } \\
\text { measurements through } \\
\text { the atmospheric } \\
\text { boundary layer. }\end{array}$ & $\begin{array}{l}\text { Infrared probe for } \\
\text { measuring sea } \\
\text { surface temperature. } \\
\text { Synthetic aperture } \\
\text { radar (SAR) for } \\
\text { measuring ocean } \\
\text { currents (along track } \\
\text { interferometry). }\end{array}$ \\
\hline $\begin{array}{l}\text { Methane, carbon dioxide } \\
\text { and nitrous oxide } \\
\text { concentrations }\end{array}$ & \\
\hline
\end{tabular}

- $\quad \mathrm{CH} 4, \mathrm{CO} 2$ and $\mathrm{N} 2 \mathrm{O}$ sensors for in situ concentrations and flux estimates from cavity ring-down laser absorption instruments.

There are choices on technology that will encourage successful mapping. Popular suggestions were the use a compact, all-in-one ground station that can be transported in a rugged case for use in harsh environments [10], ensuring the platform includes a gimbal to keep image quality resistant to wind [28], and expand the survey to cover beyond the area of interest because accuracy of UAV products distort at the edges [86], and ensure your images will have sufficient overlap. Additionally, for preflight planning, Barnas et al. [85] suggested fixed-wing systems' stability is optimized by flying directed to the crosswind rather than into headwind or tailwind. For multirotors flying into headwinds, slanting the rotors by 20 degrees can reduce upwards pitching by 26\% [137]. Heavy, bulky equipment should be avoided, such as the Sirius Pro from MAVinci, the UX5 from Trimble, of the Q-200 from Quest UAS for applications in high elevation [34]. As mentioned previously, some of the UAV exteriors were reinforced to handle landing or limited visibility in harsh environments. As previously mentioned, 
cold temperatures pose a threat for batteries by degrading voltage. Therefore, batteries must be transported in a heated environment and not be exposed unnecessarily until use. Other flight concerns involve extreme magnetic declination in polar areas, which can cause autopilot functions to fail and dictate flights to be performed manually [7].

In typical applications, to ensure accurate SfM products optimal flight-day characteristics would include wind speeds less than $10 \mathrm{~m} / \mathrm{s}$ and a high solar elevation angle [138]. However, high sun conditions may cause homogenous surfaces such as snow fields to act as specular reflective resulting in low-texture images, which will hamper the generation of dense point clouds when using popular SfM algorithms [130]. Overcast skies could alleviate distortions associated with shadows and snow backscatter though some sensors such as the default DJI Phantom 3 Professional camera, which was found to be limited by poor lighting conditions [74]. Harder et al. [28] also noted that homogenous snow surfaces were difficult to process, but they experienced most consistent performance of estimating snow depth with clear skies and high sun angles. On southerly mountain slopes and homogenous snow, clear skies were favorable for high snow cover extent (fraction) with limited snow surface brightness contrast, yet during snowmelt, which included a reduced snow cover fraction, diffused light may be favorable as clear sky conditions caused overexposure of snow pixels and errors in the point cloud. Environmental illumination preference is determined by the condition of the study target; therefore, a bit of trial-and-error is recommended per individual study. Another way to remedy the illumination influence is to properly set the camera exposure time and store imagery in RAW format using the full bit depth of the sensor (usually 10 to 14 bits) [34]. Additional benefits of RAW format are lossless storage of images [139] and increased flexibility during post-processing; specifically when correcting for exposure parameters that becomes necessary to balance bright snow aside dark rocky areas [107]. Further, the inclusion of oblique imagery can promote accurate DSM construction (see James and Robson, [140]). For multitemporal studies, illumination differences between data collection times will, understandably, effect optical band reflectance values. To overcome this issue, Rohner et al. [104] used DSMs to derive shaded reliefs rather than reflectance for inputs to Pix4D's image matching algorithm, which minimized matching errors for data collected on separate days.

Ground control points (GCPs) were a large topic of conversation for many of the studies. Though it has been previously expected that increasing the number of GCPs increases the resulting accuracy [141], in practice, accuracy and number of GCPs do not follow a linear relationship [142]. Within the surveyed cryosphere studies, it has been found that the accuracy of processed products increased asymptotically with increasing number of GCPs until a threshold was reached [60]. Tonkin and Midgley [143] found that once this threshold was exceeded (in their case, 8 GCPs, although this will vary depending on the topography, size of area and method to establish GNSS position [116]), vertical error accuracy of DSMs slightly decreased. Both studies found that vertical accuracy of DSMs diminish with increasing distance from GCPs; therefore, well distributed GCPs are recommended. The best method for applying GCPs evenly among a study area is in a triangular mesh grid to minimize the distance to surrounding GCPs [144]. Both positional quality and quantity of GCPs need to be balanced, because the angle between GCPs can also influence image processing due to the angle calculation during the bundle adjustment process [142]. The goldilocks GCP quantity is buffered within a notion of diminishing returns and a low number of GCPs (i.e., 3 -5) that can drastically underestimate RMSE [144] along with providing inadequate tie points for indirect georeferencing.

For some areas, collecting GCPs can be unrealistic, such as in dangerous avalanche areas [40], large areas of risky glacial surface [66], or sea ice applications where these GCPs move and are, therefore, useless [89]. Bühler et al. [33] noted three methods for referencing approaches and a fourth contributed by Tziavou et al. [116];

(1) Absolute referencing with placed GCPs measured with differential GNSS.

(2) Relative referencing with natural reference points that are well visible in snow-free and snow-covered imagery. 
(3) Absolute referencing of one DSM with differential GNSS and then relative referencing of the second DSM by identifying visible points in the second DSM.

(4) Record zero to five GCPs in support of on-board Post-Processing Kinematic (PPK) and Real-Time Kinematic (RTK) technology.

While the first point above is most preferable for the highest positional accuracy, manually distributing GCPs equally over the entire survey area and including all elevation bands may not be possible due to the site's terrain. It is also possible that artificial targets may move due to wind or other factors during data collection and will likely have to be reset for each flight. The following two points are only applicable if there are stable features not covered by snow. If conventional GCPs are not viable, the preferred method would be to have a GPS/GNSS to record position and inertial measurement unit (IMU) to compute image rotation aboard the UAV with a preferred accuracy of less than $0.05 \mathrm{~m}$, following option four as mentioned above [24]. This approach used in Harder et al. [28] and Schirmer and Pomeroy [95] quantified snow depth for different terrain types via a Canon PowerShot ELPH 110 HS camera aboard a fixed-wing SenseFly eBee. The platform was bundled with flight control and image processing software, using a Leica GS15 base station to supply corrections to the eBee, resolving image locations within $2.5 \mathrm{~cm}$ accuracy. They tested the accuracy of DSMs with and without GCPs for their study sites. From a total of 31 flights at $90 \mathrm{~m}$ altitude (GSD $3 \mathrm{~cm} /$ pixel), the inclusion of GCPs had little effect on the standard deviation of error with respect to surface observations. However, the GCPs had a larger effect in reducing the mean absolute error from 27 to $10 \mathrm{~cm}$ for prairie and from 14 to $6 \mathrm{~cm}$ for an alpine site. The GCP-included DSM errors translated to mean snow depth errors of $8.8,13.7$ and $8.5 \mathrm{~cm}$ over the short and tall prairie and alpine sites, respectively [28]. Therefore, the highest level of accuracy is currently achievable by utilizing GCPs and this result is corroborated within UAV photogrammetry-specific literature [144]. Still, DSMs have been produced for cryosphere studies excluding GCPs in lieu of RTK capabilities of the Sensefly eBee [37,38]. Due to common inaccessibility of applying manual GCPs, this technique of data collection is likely to gain popularity. However, specific RTK technology is not completely necessary. Goreferencing without the use of ground control points is dependent on the accuracy of photo positions. This can be achieved using an on-board, high-quality (within centimeter capability) GPS and exact time that each photo was taken to determine each photo's position during post-processing. Nolan et al. [111] utilized this method on a manned vehicle using a consumer-grade RGB camera and without the use of ground control points or IMU created difference DSMs for determining snow depth that were statistically identical with $10 \mathrm{~cm}$ standard deviation to 6000+ hand-probed snow depth measurements. Admittedly, the exclusion of an IMU introduces the assumption that the aircraft frame of reference is aligned with the tangent of the trajectory; GNSS can be added aboard UAVs to offer similar capabilities, as was demonstrated using a Skywalker fixed-wing above Store Glacier, a large marine-terminating glacier in Greenland [139].

To minimize gaps and encourage accuracy in orthomosaic products, image forward- and side-lap of $80 \%-85 \%$ is recommended [116,145]. Achieving this will depend on flight altitude, but for many studies, this was equivalent to taking one picture every second, flying at 8-10 m per second. Several studies applied this standard although many opted for $70 \%$ forward and $60 \%$ side-lap or less $[57,61,88]$. Alfredsen et al. [74] utilized a minimal image overlap of $20 \%$, which was the least amount of coverage found within the reviewed papers. Experienced investigators and some multitemporal studies initially employed minimal overlap and switched to higher overlap in later flights, suggesting increased success with the more conservative approach (e.g., $[38,75,83])$. Additional considerations for flight planning are to keep flight orientation consistent among repeated flights to maintain shadow location and to follow parallel tracks because cross-tracks add extra flight time and have been found to be unhelpful in increasing point cloud density or accuracy if adequate control points are available [94,118]. Finally, van der Sluijs et al. [91] recommended a methodology that includes a minimum and optimized GNSS-based GCP/CP network, and if available, incorporates regional high-resolution airborne laser scanning topographic data to tie in fine-scale DSM-like products derived by UAV surveys. 
Many organizations have produced recommendations to aid in the increasing contribution of UAVs for scientific research and environmental monitoring. The Arctic Monitoring and Assessment Programme (AMAP) has produced operator handbooks that are available for download. The handbooks include UAV airspace access and regulation information for important regions for cryosphere research, though users should consult direct sources for updates on UAV regulations $[136,146]$. Support materials related to marine operations of UAVs are available through the Scientific Committee for Oceanographic Aircraft Research (SCOAR), organized through the University-National Oceanographic Laboratory System [147]. The Council of Managers of National Antarctic Programs (COMNAP) and the Scientific Committee on Antarctic Research (SCAR) have each contributed recommendations for guidelines for UAVs in Antarctica with encouragement from the Antarctic Treaty Consultative Meetings (ATCM) and Committee for Environmental Protection (CEP) [148]. The recommendations covered include record keeping of flights and accident incident reporting, identification on all major components of the $\mathrm{UAV}$, and routine sharing of operational and certification information in support of facilitating best practices [149].

\section{Conclusion}

This review tracked the applications, methods, technologies, and recommendations of over 100 recent studies of the cryosphere that utilized UAVs as a major contributor of data collection. The goal of this review is to take a snapshot of the quickly evolving field, record what is notable and popular within this sector, and provide recommendations for future investigators. By dissecting the many examples of UAVs usage for cryospheric research, it is easy to see that there is plenty of opportunity for the technology to fill current research voids. For example, Zmarz et al. [4] concluded the spatial variability induced by the complex morphology of the terrain made mapping Antarctic vegetation "extremely difficult" with satellite products. Other compounding factors were the patchy and mosaic character of micro-habitats and extreme differentiation caused by abiotic features, specifically water conditions, salinity and the nutrient content of the substratum. Even high-resolution satellite imagery of $0.5 \mathrm{~m}$ was unsuitable for mapping tundra extent in sufficient detail [4]. Additionally, field measurements of these require human disturbance such as footprints on fragile mosses that cannot recover quickly [9]. Therefore, UAVs fill a gap in aerial analysis of these biomes, as well as many other useful environmental applications. The dearth of submeter-resolution multispectral or infrared remote sensing data in the public domain poses many limitations for cryospheric research. Even paid one-time datasets are insufficient as the cryosphere is evolving continuously in the presently changing climates and requires repetitive imaging and analyses for deriving meaningful inferences. Moreover, there are even fewer satellite remote sensors equipped with stereo-viewing capabilities. Thus, the exploration and advancement of the immense capabilities of UAVs for cryospheric research is much needed and the $100+$ studies compiled and analyzed in this review signifies that we are moving in the right direction. Various reputed scientific journals are now providing fully citable data submission platforms and we believe that this can encourage mutual UAV data sharing amongst cryospheric researchers at a global scale.

Author Contributions: C.G. and A.B. conceptualized, collected papers and performed the literature survey. C.G. performed the major writing of this manuscript and the final editorial adjustments. A.B. provided suggestions that improved the quality of the review. All authors have read and agreed to the published version of the manuscript.

Funding: This research received no external funding.

Acknowledgments: We would like to thank Karen Frey who provided great support with the initiation of the review paper and the reviewers who provided feedback that strengthened the review in its final form.

Conflicts of Interest: The authors declare no conflict of interest. 


\section{References}

1. Bhardwaj, A.; Sam, L.; Akanksha; Martín-Torres, F.J.; Kumar, R. UAVs as Remote Sensing Platform in Glaciology: Present Applications and Future Prospects. Remote Sens. Environ. 2016, 175, 196-204. [CrossRef]

2. Wigmore, O.; Mark, B. Monitoring Tropical Debris Covered Glacier Dynamics from High Resolution Unmanned Aerial Vehicle Photogrammetry, Cordillera Blanca, Peru. Cryosphere 2017, 11, 2463-2480. [CrossRef]

3. Ancel, A.; Cristofari, R.; Fretwell, P.T.; Trathan, P.N.; Wienecke, B.; Boureau, M.; Morinay, J.; Blanc, S.; Le Maho, Y.; Le Bohec, C. Emperors in Hiding: When Ice-Breakers and Satellites Complement Each Other in Antarctic Exploration. PLoS ONE 2014, 9, 9. [CrossRef] [PubMed]

4. Zmarz, A.; Rodzewicz, M.; Dabski, M.; Karsznia, I.; Korczak-Abshire, M.; Chwedorzewska, K.J. Application of UAV BVLOS Remote Sensing Data for Multi-Faceted Analysis of Antarctic Ecosystem. Remote Sens. Environ. 2018, 217, 375-388. [CrossRef]

5. Leary, D. Drones on Ice: An Assessment of the Legal Implications of the Use of Unmanned Aerial Vehicles in Scientific Research and by the Tourist Industry in Antarctica. Polar Rec. 2017, 53, 343-357. [CrossRef]

6. Watts, A.C.; Ambrosia, V.G.; Hinkley, E.A. Unmanned Aircraft Systems in Remote Sensing and Scientific Research: Classification and Considerations of Use. Remote Sens. 2012, 4, 1671-1692. [CrossRef]

7. Lucieer, A.; Turner, D.; King, D.H.; Robinson, S.A. Using an Unmanned Aerial Vehicle ( UAV ) to Capture Micro-Topography of Antarctic Moss Beds Using an Unmanned Aerial Vehicle ( UAV ) to Capture Micro-Topography. Int. J. Appl. Earth Obs. Geoinform. 2014, 27, 53-62. [CrossRef]

8. Turner, D.; Lucieer, A.; Malenovský, Z.; King, D.H.; Robinson, S.A. Spatial Co-Registration of Ultra-High Resolution Visible, Multispectral and Thermal Images Acquired with a Micro-UAV over Antarctic Moss Beds. Remote Sens. 2014, 6, 4003-4024. [CrossRef]

9. Bollard-Breen, B.; Brooks, J.D.; Jones, M.R.L.; Robertson, J.; Betschart, S.; Kung, O.; Craig Cary, S.; Lee, C.K.; Pointing, S.B. Application of an Unmanned Aerial Vehicle in Spatial Mapping of Terrestrial Biology and Human Disturbance in the McMurdo Dry Valleys, East Antarctica. Polar Biol. 2015, 38, 573-578. [CrossRef]

10. Goebel, M.E.; Perryman, W.L.; Hinke, J.T.; Krause, D.J.; Hann, N.A.; Gardner, S.; LeRoi, D.J. A Small Unmanned Aerial System for Estimating Abundance and Size of Antarctic Predators. Polar Biol. 2015, 38, 619-630. [CrossRef]

11. Vander Jagt, B.; Lucieer, A.; Wallace, L.; Turner, D.; Durand, M. Snow Depth Retrieval with UAS Using Photogrammetric Techniques. Geosciences 2015, 5, 264-285. [CrossRef]

12. Jonassen, M.O.; Tisler, P.; Altsta, B.; Scholtz, A.; Vihma, T.; Lampert, A.; Konig-Langlo, G.; Lupkes, C. Application of Remotely Piloted Aircraft Systems in Observing the Atmospheric Boundary Layer over Antarctic Sea Ice in Winter. Polar Res. 2015, 34, 25651. [CrossRef]

13. Steiner, J.F.; Pellicciotti, F.; Buri, P.; Miles, E.S.; Immerzeel, W.W.; Reid, T.D. Modelling Ice-Cliff Backwasting on a Debris-Covered Glacier in the Nepalese Himalaya. J. Glaciol. 2015, 61, 889-907. [CrossRef]

14. Immerzeel, W.W.; Kraaijenbrink, P.D.A.; Shea, J.M.; Shrestha, A.B.; Pellicciotti, F.; Bierkens, M.F.P.; Jong, S.M.D. High-Resolution Monitoring of Himalayan Glacier Dynamics Using Unmanned Aerial Vehicles. Remote Sens. Environ. 2014, 150, 93-103. [CrossRef]

15. Cimoli, E. Determining Snow Depth Distribution from Unmanned Aerial Vehicles and Digital Photogrammetry. Master Thesis, Technical University of Denmark (DTU), Lyngby, Denmark, August 2015.

16. Cimoli, E.; Marcer, M.; Vandecrux, B.; Bøggild, C.E.; Williams, G.D.; Simonsen, S.B. Application of Low-Cost UASs and Digital Photogrammetry for High-Resolution Snow Depth Mapping in the Arctic. Remote. Sens. 2017, 9, 1144. [CrossRef]

17. Westoby, M.; Dunning, S.; Woodward, J.; Hein, A.; Marrero, S.; Winter, K.; Sugden, D. Sedimentological Characterization of Antarctic Moraines Using UAVs and Structure-from-Motion Photogrammetry. J. Glaciol. 2015, 61, 1088-1102. [CrossRef]

18. Westoby, M.J.; Dunning, S.A.; Woodward, J.; Hein, A.S.; Marrero, S.M.; Winter, K.; Sugden, D.E. Interannual Surface Evolution of an Antarctic Blue-Ice Moraine Using Multi-Temporal DEMs. Earth Surf. Dyn. 2016, 4, 515-529. [CrossRef]

19. De Michele, C.; Avanzi, F.; Passoni, D.; Barzaghi, R.; Pinto, L.; Dosso, P.; Ghezzi, a.; Gianatti, R.; Della Vedova, G. Microscale Variability of Snow Depth Using U.A.S. Technology. Cryosph. Discuss. 2015, 9, 1047-1075. [CrossRef] 
20. De Michele, C.; Avanzi, F.; Passoni, D.; Barzaghi, R.; Pinto, L.; Dosso, P.; Ghezzi, A.; Gianatti, R.; Vedova, G. Della. Using a Fixed-Wing UAS to Map Snow Depth Distribution: An Evaluation at Peak Accumulation. Cryosphere 2016, 10, 511-522. [CrossRef]

21. Stuchlík, R.; Stachoň, Z.; Láska, K.; Kubíček, P. Unmanned Aerial Vehicle-Efficient Mapping Tool Available for Recent Research in Polar Regions. Czech Polar Rep. 2016, 5, 210-221. [CrossRef]

22. Buri, P.; Pellicciotti, F.; Steiner, J.F.; Miles, E.S.; Immerzeel, W.W. A Grid-Based Model of Backwasting of Supraglacial Ice Cliffs on Debris-Covered Glaciers. Ann. Glaciol. 2016, 57, 199-211. [CrossRef]

23. Pedersen, S.H.; Tamstorf, M.P.; Abermann, J.; Westergaard-Nielsen, A.; Lund, M.; Skov, K.; Sigsgaard, C.; Mylius, M.R.; Hansen, B.U.; Liston, G.E.; et al. Spatiotemporal Characteristics of Seasonal Snow Cover in Northeast Greenland from in Situ Observations. Arctic, Antarct. Alp. Res. 2016, 48, 653-671. [CrossRef]

24. Boesch, R.; Bühler, Y.; Marty, M.; Ginzler, C. Comparison of Digital Surface Models for Snow Depth Mapping with Uav and Aerial Cameras. ISPRS Int. Arch. Photogramm. Remote. Sens. Spat. Inf. Sci. 2016, 41, 453-458. [CrossRef]

25. Ewertowski, M.W.; Evans, D.J.A.; Roberts, D.H.; Tomczyk, A.M. Glacial Geomorphology of the Terrestrial Margins of the Tidewater Glacier, Nordenskiöldbreen, Svalbard. J. Maps 2016, 12, 476-487. [CrossRef]

26. Evans, D.J.; Ewertowski, M.W.; Orton, C. Fláajökull (north lobe), Iceland: Active temperate piedmont lobe glacial landsystem. J. Maps 2015, 12, 777-789. [CrossRef]

27. Tonkin, T.; Midgley, N.; Cook, S.J.; Graham, D. Ice-cored moraine degradation mapped and quantified using an unmanned aerial vehicle: A case study from a polythermal glacier in Svalbard. Geomorphology 2016, 258, 1-10. [CrossRef]

28. Harder, P.; Schirmer, M.; Pomeroy, J.; Helgason, W. Accuracy of snow depth estimation in mountain and prairie environments by an unmanned aerial vehicle. Cryosphere 2016, 10, 2559-2571. [CrossRef]

29. Vincent, C.; Wagnon, P.; Shea, J.; Immerzeel, W.W.; Kraaijenbrink, P.D.A.; Shrestha, D.; Soruco, A.; Arnaud, Y.; Brun, F.; Berthier, E.; et al. Reduced melt on debris-covered glaciers: Investigations from Changri Nup Glacier, Nepal. Cryosphere 2016, 10, 1845-1858. [CrossRef]

30. Kraaijenbrink, P.D.A.; Shea, J.; Pellicciotti, F.; De Jong, S.; Immerzeel, W.W. Object-based analysis of unmanned aerial vehicle imagery to map and characterise surface features on a debris-covered glacier. Remote. Sens. Environ. 2016, 186, 581-595. [CrossRef]

31. Brun, F.; Buri, P.; Miles, E.; Wagnon, P.; Steiner, J.F.; Berthier, E.; Ragettli, S.; Kraaijenbrink, P.D.A.; Immerzeel, W.W.; Pellicciotti, F. Quantifying volume loss from ice cliffs on debris-covered glaciers using high-resolution terrestrial and aerial photogrammetry. J. Glaciol. 2016, 62, 684-695. [CrossRef]

32. Brun, F.; Wagnon, P.; Berthier, E.; Shea, J.; Immerzeel, W.W.; Kraaijenbrink, P.D.A.; Vincent, C.; Reverchon, C.; Shrestha, D.; Arnaud, Y. Ice cliff contribution to the tongue-wide ablation of Changri Nup Glacier, Nepal, central Himalaya. Cryosphere 2018, 12, 3439-3457. [CrossRef]

33. Bühler, Y.; Adams, M.S.; Bösch, R.; Stoffel, A. Mapping snow depth in alpine terrain with unmanned aerial systems (UASs): Potential and limitations. Cryosphere 2016, 10, 1075-1088. [CrossRef]

34. Bühler, Y.; Adams, M.; Stoffel, A.; Boesch, R. Photogrammetric reconstruction of homogenous snow surfaces in alpine terrain applying near-infrared UAS imagery. Int. J. Remote. Sens. 2017, 38, 3135-3158. [CrossRef]

35. Rümmler, M.-C.; Mustafa, O.; Maercker, J.; Hans-Ulrich, P.; Esefeld, J. Measuring the Influence of Unmanned Aerial Vehicles ' Lie Penguins on Adelie Penguins. Polar Biol. 2016, 39, 1329-1334. [CrossRef]

36. Rümmler, M.C.; Mustafa, O.; Maercker, J.; Peter, H.U.; Esefeld, J. Sensitivity of Adélie and Gentoo Penguins to Various Flight Activities of a Micro UAV. Polar Biol. 2018, 41, 2481-2493. [CrossRef]

37. Lambiel, C.; Rüttimann, S.; Meyrat, R.; Vivero, S. Capturing the Crisis of an Active Rock Glacier with UAV Survey. In Proceedings of the 19th EGU General Assembly, EGU2017, Vienna, Austria, 23-29 April 2017; p. 7014.

38. Dall'Asta, E.; Forlani, G.; Roncella, R.; Santise, M.; Diotri, F.; Morra di Cella, U. Unmanned Aerial Systems and DSM Matching for Rock Glacier Monitoring. ISPRS J. Photogramm. Remote Sens. 2016, 127, 102-114. [CrossRef]

39. Telg, H.; Murphy, D.M.; Bates, T.S.; Johnson, J.E.; Quinn, P.K.; Giardi, F.; Gao, R.-S. A Practical Set of Miniaturized Instruments for Vertical Profiling of Aerosol Physical Properties. Aerosol Sci. Technol. 2017, 51, 715-723. [CrossRef] 
40. Miziński, B.; Niedzielski, T. Fully-Automated Estimation of Snow Depth in near Real Time with the Use of Unmanned Aerial Vehicles without Utilizing Ground Control Points. Cold Reg. Sci. Technol. 2017, 138, 63-72. [CrossRef]

41. Phillips, E.; Everest, J.; Evans, D.J.A.; Finlayson, A.; Ewertowski, M.; Guild, A.; Jones, L. Concentrated, 'Pulsed' Axial Glacier Flow: Structural Glaciological Evidence from Kvíárjökull in SE Iceland. Earth Surf. Process. Landforms 2017, 42, 1901-1922. [CrossRef]

42. Nehyba, S.; Hanáček, M.; Engel, Z.; Stachoň, Z. Rise and Fall of a Small Ice-Dammed Lake-Role of Deglaciation Processes and Morphology. Geomorphology 2017, 295, 662-679. [CrossRef]

43. Mustafa, O.; Esefeld, J.; Grämer, H.; Maercker, J.; Peter, H.-U.; Rümmler, M.-C.; Senf, M.; Pfeifer, C.; Hans-Ulrich, P. Monitoring Penguin Colonies in the Antarctic Using Remote Sensing Data; Hertel, F., Ed.; Umweltbundesamt: Jena, Germany, 2017.

44. Mustafa, O.; Barbosa, A.; Krause, D.J.; Peter, H.-U.; Vieira, G.; Rümmler, M.-C. State of Knowledge: Antarctic Wildlife Response to Unmanned Aerial Systems. Polar Biol. 2018, 41, 2387-2398. [CrossRef]

45. Liang, H.; Huang, X.; Sun, Y.; Wang, Y.; Liang, T. Fractional Snow-Cover Mapping Based on MODIS and UAV Data over the Tibetan Plateau. Remote Sens. 2017, 9, 1332. [CrossRef]

46. Smith, L.C.; Yang, K.; Pitcher, L.H.; Overstreet, B.T.; Chu, V.W.; Rennermalm, Å. K.; Ryan, J.C.; Cooper, M.G.; Gleason, C.J.; Tedesco, M.; et al. Direct Measurements of Meltwater Runoff on the Greenland Ice Sheet Surface. Proc. Natl. Acad. Sci. USA 2017, 114, E10622-E10631. [CrossRef] [PubMed]

47. Ryan, J.C.; Hubbard, A.; Box, J.E.; Todd, J.A.; Christoffersen, P.; Carr, J.R.; Holt, T.O.; Snooke, N. UAV photogrammetry and structure from motion to assess calving dynamics at Store Glacier, a large outlet draining the Greenland ice sheet. Cryosphere 2015, 9, 1-11. [CrossRef]

48. Busker, T. A New Methodology for Measuring Ice Cliff Backwasting Rates on Debris-Covered Glaciers Using High-Resolution Unmanned Aerial Vehicle Imagery. Master's Thesis, Utrecht University, Utrecht, The Netherlands, January 2017.

49. Ader, M.; Axelsson, D. Drones in Arctic Environments. Master's Thesis, KTH Royal Institute of Technology, Stockholm, Sweden, 14 September 2017.

50. Lovitt, J.; Rahman, M.M.; McDermid, G.J. Assessing the Value of UAV Photogrammetry for Characterizing Terrain in Complex Peatlands. Remote Sens. 2017, 9, 715. [CrossRef]

51. Burkhart, J.F.; Kylling, A.; Schaaf, C.; Wang, Z.; Bogren, W.; Storvold, R.; Solbø, S.; Pedersen, C.A.; Gerland, S. Unmanned aerial system nadir reflectance and MODIS nadir BRDF-adjusted surface reflectances intercompared over Greenland. Cryosphere 2017, 11, 1575-1589. [CrossRef]

52. Bernard, E.; Friedt, J.M.; Tolle, F.; Grieslin, M.; Marlin, C.; Prokop, A. Investigating Snowpack Volumes and Icing Dynamics in the Moraine of an Arctic Catchment Using UAV Photogrammetry. Photogramm. Rec. 2017, 32, 497-512. [CrossRef]

53. Bernard, E.; Friedt, J.M.; Tolle, F.; Marlin, C.; Griselin, M. Using a Small COTS UAV to Quantify Moraine Dynamics Induced by Climate Shift in Arctic Environments. Int. J. Remote Sens. 2017, 38, 2480-2494. [CrossRef]

54. Ely, J.C.; Graham, C.; Barr, I.D.; Rea, B.R.; Spagnolo, M.; Evans, J. Using UAV Acquired Photography and Structure from Motion Techniques for Studying Glacier Landforms: Application to the Glacial Flutes at Isfallsglaciären. Earth Surf. Process. Landforms 2017, 42, 877-888. [CrossRef]

55. Krause, D.J.; Hinke, J.T.; Perryman, W.L.; Goebel, M.E.; LeRoi, D.J. An Accurate and Adaptable Photogrammetric Approach for Estimating the Mass and Body Condition of Pinnipeds Using an Unmanned Aerial System. PLoS ONE 2017, 12, 1-21. [CrossRef]

56. Malenovský, Z.; Lucieer, A.; King, D.H.; Turnbull, J.D.; Robinson, S.A. Unmanned Aircraft System Advances Health Mapping of Fragile Polar Vegetation. Methods Ecol. Evol. 2017, 8, 1842-1857. [CrossRef]

57. Dąbski, M.; Zmarz, A.; Pabjanek, P.; Korczak-Abshire, M.; Karsznia, I.; Chwedorzewska, K.J. UAV-Based Detection and Spatial Analyses of Periglacial Landforms on Demay Point (King George Island, South Shetland Islands, Antarctica). Geomorphology 2017, 290, 29-38. [CrossRef]

58. Jouvet, G.; Weidmann, Y.; Seguinot, J.; Funk, M.; Abe, T.; Sakakibara, D.; Seddik, H.; Sugiyama, S. Initiation of a Major Calving Event on the Bowdoin Glacier Captured by UAV Photogrammetry. Cryosphere 2017, 11, 911-921. [CrossRef] 
59. Seier, G.; Kellerer-Pirklbauer, A.; Wecht, M.; Hirschmann, S.; Kaufmann, V.; Lieb, G.K.; Sulzer, W. UAS-Based Change Detection of the Glacial and Proglacial Transition Zone at Pasterze Glacier, Austria. Remote Sens. 2017, 9, 1-19. [CrossRef]

60. Gindraux, S.; Boesch, R.; Farinotti, D. Accuracy Assessment of Digital Surface Models from Unmanned Aerial Vehicles' Imagery on Glaciers. Remote Sens. 2017, 9, 1-15. [CrossRef]

61. Ryan, J.C.; Hubbard, A.; Box, J.E.; Brough, S.; Cameron, K.; Cook, J.M.; Cooper, M.; Doyle, S.H.; Edwards, A.; Holt, T.O.; et al. Derivation of High Spatial Resolution Albedo from UAV Digital Imagery: Application over the Greenland Ice Sheet. Front. Earth Sci. 2017, 5, 5. [CrossRef]

62. Scaioni, M.; Corti, M.; Diolaiuti, G.; Fugazza, D.; Cernuschi, M. Local and General Monitoring of Forni Glacier (Italian Alps) Using Multi-Platform Structure-From-Motion Photogrammetry. ISPRS Int. Arch. Photogramm. Remote. Sens. Spat. Inf. Sci. 2017, 42, 1547-1554. [CrossRef]

63. Scaioni, M.; Barazzetti, L.; Corti, M.; Crippa, J.; Azzoni, R.S.; Fugazza, D.; Cernuschi, M.; Diolaiuti, G. Integration of Terrestrial And Uav Photogrammetry for The Assessment of Collapse Risk in Alpine Glaciers. ISPRS Int. Arch. Photogramm. Remote. Sens. Spat. Inf. Sci. 2018, XLII-3/W4, 445-452. [CrossRef]

64. Weimerskirch, H.; Pudor, A.; Schull, Q. Flights of Drones over Sub-Antarctic Seabirds Show Species- and Status-Specific Behavioural and Physiological Responses. Polar Biol. 2018, 41, 259-266. [CrossRef]

65. Lousada, M.; Pina, P.; Vieira, G.; Bandeira, L.; Mora, C. Evaluation of the Use of Very High Resolution Aerial Imagery for Accurate Ice-Wedge Polygon Mapping (Adventdalen, Svalbard). Sci. Total Environ. 2018, 615, 1574-1583. [CrossRef]

66. Jones, C.; Ryan, J.; Holt, T.; Hubbard, A. Structural Glaciology of Isunguata Sermia, West Greenland. J. Maps 2018, 14, 517-527. [CrossRef]

67. Cooper, M.G.; Smith, L.C.; Rennermalm, A.K.; Miège, C.; Ryan, J.C.; Pitcher, L.H.; Cooley, S.; Yang, K. Near Surface Meltwater Storage in Low-Density Bare Ice of the Greenland Ice Sheet Ablation Zone. Cryosph. Discuss. 2017, 1-25. [CrossRef]

68. Cooper, M.G.; Smith, L.C.; Rennermalm, A.K.; Miège, C.; Pitcher, L.H.; Ryan, J.C.; Yang, K.; Cooley, S.W. Meltwater Storage in Low-Density near-Surface Bare Ice in the Greenland Ice Sheet Ablation Zone. Cryosphere 2018, 12, 955-970. [CrossRef]

69. Yang, K.; Smith, L.C.; Karlstrom, L.; Cooper, M.G.; Tedesco, M.; van As, D.; Cheng, X.; Chen, Z.; Li, M. Supraglacial Meltwater Routing through Internally Drained Catchments on the Greenland Ice Sheet Surface. Cryosph. Discuss. 2018, 1-32. [CrossRef]

70. Yang, K.; Smith, L.C.; Karlstrom, L.; Cooper, M.; Tedesco, M.; Van As, D.; Cheng, X.; Chen, Z.; Li, M. A new surface meltwater routing model for use on the Greenland Ice Sheet surface. Cryosphere 2018, 12, 3791-3811. [CrossRef]

71. De Boer, G.; Ivey, M.; Schmid, B.; Lawrence, D.; Dexheimer, D.; Mei, F.; Hubbe, J.; Bendure, A.; Hardesty, J.; Shupe, M.D.; et al. A Bird's-Eye View: Development of an Operational ARM Unmanned Aerial Capability for Atmospheric Research in Arctic Alaska. Bull. Am. Meteorol. Soc. 2018, 99, 1197-1212. [CrossRef]

72. Fugazza, D.; Scaioni, M.; Corti, M.; D’Agata, C.; Azzoni, R.S.; Cernuschi, M.; Smiraglia, C.; Diolaiuti, G.A. Combination of UAV and Terrestrial Photogrammetry to Assess Rapid Glacier Evolution and Conditions of Glacier Hazards. Nat. Hazards Earth Syst. Sci. 2018, 18, 1055-1071. [CrossRef]

73. Jouvet, G.; Weidmann, Y.; Kneib, M.; Detert, M.; Seguinot, J.; Sakakibara, D.; Sugiyama, S. Short-Lived Ice Speed-up and Plume Water Flow Captured by a VTOL UAV Give Insights into Subglacial Hydrological System of Bowdoin Glacier. Remote Sens. Environ. 2018, 217, 389-399. [CrossRef]

74. Alfredsen, K.; Haas, C.; Tuhtan, J.A.; Zinke, P. Brief Communication: Mapping River Ice Using Drones and Structure from Motion. Cryosphere 2018, 12, 627-633. [CrossRef]

75. Mather, A.; Fyfe, R.; Clason, C.; Stokes, M.; Mills, S.; Barrows, T.T. Automated mapping of relict patterned ground: An approach to evaluate morphologically subdued landforms using unmanned-aerial-vehicle and structure-from-motion technologies. Prog. Phys. Geogr. Earth Environ. 2018, 43, 174-192. [CrossRef]

76. Tan, A.E.-C.; Eccleston, K.; Platt, I.; Woodhead, I.; Rack, W.; Mc Culloch, J. Microwave Measurements of Snow Over Sea-Ice in Antarctica. In Proceedings of the 2018 12th International Conference on Electromagnetic Wave Interaction with Water and Moist Substances (ISEMA), Lublin, Poland, 4-7 June 2018; Institute of Electrical and Electronics Engineers (IEEE): Piscataway, NJ, USA, 2018; pp. 1-9.

77. Gonzalez, P.J.; Zhang, Y.; Samsonov, S. Quantitative Morphological Description of Pingos (Permafrost Hills) Using High-Resolution DEMs from UAV and Satellite Photogrammetry. Geophys. Res. Abstr. 2018, 20, 18481. 
78. Midgley, N.G.; Tonkin, T.N.; Graham, D.J.; Cook, S.J. Evolution of High-Arctic Glacial Landforms during Deglaciation. Geomorphology 2018, 311, 63-75. [CrossRef]

79. Florinsky, I.V.; Bliakharskii, D.P. Crevasse Detection by Geomorphometric Modelling of Data from Unmanned Aerial Survey. Proceedings of International Youth Scientific Conference on the Polar Geodesy, Glaciology, Hydrology and Geophysics, St. Petersburg, Russia, 17-19 May 2018; pp. 247-255.

80. Bliakharskii, D.; Florinsky, I. Unmanned Aerial Survey for Modelling Glacier Topography in Antarctica: First Results. In Proceedings of the 4th International Conference on Geographical Information Systems Theory, Applications and Management, Madeira, Portugal, 17-19 March 2018; pp. 319-326.

81. Isacsson, M. Snow Layer Mapping by Remote Sensing from Unmanned Aerial Vehicles. Master's Thesis, KTH Royal Institute of Technology, Stockholm, Sweden, 2017.

82. Attalla, D.; Tang, A. Drones in Arctic Environments: Snow Change Tracking Aid Using Sensor Fusion. Master's Thesis, KTH Royal Institute of Technology, Stockholm, Sweden, 2018.

83. Adams, M.S.; Bühler, Y.; Fromm, R. Multitemporal Accuracy and Precision Assessment of Unmanned Aerial System Photogrammetry for Slope-Scale Snow Depth Maps in Alpine Terrain. Pure Appl. Geophys. 2018, 175, 3303-3324. [CrossRef]

84. Luo, L.; Ma, W.; Zhao, W.; Zhuang, Y.; Zhang, Z.; Zhang, M.; Ma, D.; Zhou, Q. UAV-Based Spatiotemporal Thermal Patterns of Permafrost Slopes along the Qinghai-Tibet Engineering Corridor. Landslides 2018, 15, 2161-2172. [CrossRef]

85. Barnas, A.F.; Felege, C.J.; Rockwell, R.F.; Ellis-Felege, S.N. A Pilot(Less) Study on the Use of an Unmanned Aircraft System for Studying Polar Bears (Ursus Maritimus). Polar Biol. 2018, 41, 1055-1062. [CrossRef]

86. Rossini, M.; Di Mauro, B.; Garzonio, R.; Baccolo, G.; Cavallini, G.; Mattavelli, M.; De Amicis, M.; Colombo, R. Rapid Melting Dynamics of an Alpine Glacier with Repeated UAV Photogrammetry. Geomorphology 2018, 304, 159-172. [CrossRef]

87. Kraaijenbrink, P.D.A.; Shea, J.M.; Litt, M.; Steiner, J.F.; Treichler, D.; Koch, I.; Immerzeel, W.W. Mapping Surface Temperatures on a Debris-Covered Glacier With an Unmanned Aerial Vehicle. Front. Earth Sci. 2018, 6, 64. [CrossRef]

88. Kraaijenbrink, P. High-Resolution Insights into the Dynamics of Himalayan Debris-Covered Glaciers. Ph.D. Thesis, University Utrecht, Utrecht, The Netherlands, 19 September 2018.

89. Kim, J.-I.; Kim, H.-C. Incorrect Match Detection Method for Arctic Sea-Ice Reconstruction Using UAV Images. ISPRS Int. Arch. Photogramm. Remote. Sens. Spat. Inf. Sci. 2018, 501-505. [CrossRef]

90. Kizyakov, A.; Khomutov, A.; Zimin, M.; Khairullin, R.; Babkina, E.; Dvornikov, Y.; Leibman, M. Microrelief Associated with Gas Emission Craters: Remote-Sensing and Field-Based Study. Remote Sens. 2018, 10, 677. [CrossRef]

91. Sluijs, J.V.D.; Kokelj, S.V.; Fraser, R.H.; Tunnicliffe, J.; Lacelle, D. Permafrost Terrain Dynamics and Infrastructure Impacts Revealed by UAV Photogrammetry and Thermal Imaging. Remote Sens. 2018, 10, 1734. [CrossRef]

92. Avanzi, F.; Bianchi, A.; Cina, A.; De Michele, C.; Maschio, P.; Pagliari, D.; Passoni, D.; Pinto, L.; Piras, M.; Rossi, L. Centimetric Accuracy in Snow Depth Using Unmanned Aerial System Photogrammetry and a Multistation. Remote Sens. 2018, 10, 765. [CrossRef]

93. Korczak-Abshire, M.; Zmarz, A.; Rodzewicz, M.; Kycko, M.; Karsznia, I.; Chwedorzewska, K.J. Study of Fauna Population Changes on Penguin Island and Turret Point Oasis (King George Island, Antarctica) Using an Unmanned Aerial Vehicle. Polar Biol. 2018, 42, 217-224. [CrossRef]

94. Fernandes, R.; Prevost, C.; Canisius, F.; Leblanc, S.G.; Maloley, M.; Oakes, S.; Holman, K.; Knudby, A. Monitoring Snow Depth Change across a Range of Landscapes with Ephemeral Snowpacks Using Structure from Motion Applied to Lightweight Unmanned Aerial Vehicle Videos. Croysphere. 2018, 12, 3535-3550. [CrossRef]

95. Schirmer, M.; Pomeroy, J. Factors influencing spring and summer areal snow ablation and snowcover depletion in alpine terrain: Detailed measurements from the Canadian Rockies. Hydrol. Earth Syst. Sci. Discuss. 2018, 2018, 1-31.

96. Schirmer, M.; Pomeroy, J.W. Processes Governing Snow Ablation in Alpine Terrain-Detailed Measurements from the Canadian Rockies. Hydrol. Earth Syst. Sci. 2020, 24, 143-157. [CrossRef]

97. Cook, J.M.; Sweet, M.; Cavalli, O.; Taggart, A.; Edwards, A. Topographic shading influences cryoconite morphodynamics and carbon exchange. Arctic, Antarct. Alp. Res. 2018, 50, S100014. [CrossRef] 
98. Bash, E.A.; Moorman, B.J.; Gunther, A. Detecting Short-Term Surface Melt on an Arctic Glacier Using UAV Surveys. Remote Sens. 2018, 10, 1547. [CrossRef]

99. Bash, E.A.; Moorman, B.J. Assessing the Performance of a Distributed Radiation-Temperature Melt Model on an Arctic Glacier Using UAV Data. Cryosph. Discuss. 2019, 1-17.

100. Bash, E.A.; Moorman, B.J. Surface Melt and the Importance of Water Flow-An Analysis Based on High-Resolution Unmanned Aerial Vehicle (UAV) Data for an Arctic Glacier. Croysphere. 2020, 14, 549-563. [CrossRef]

101. Jenssen, R.O.R.; Eckerstorfer, M.; Jacobsen, S.K.; Storvold, R. Drone-Mounted UWB Radar System for Measuring Snowpack Properties: Technical Implementation, Specifications and Initial Results. In Proceedings of the International Snow Science Workshop, Innsbruck, Austria, 7-12 October 2018.

102. Jenssen, R.O.R.; Eckerstorfer, M.; Jacobsen, S. Drone-Mounted Ultrawideband Radar for Retrieval of Snowpack Properties. IEEE Trans. Instrum. Meas. 2020, 69, 221-230. [CrossRef]

103. Léger, E.; Dafflon, B.; Robert, Y.; Ulrich, C.; Peterson, J.E.; Biraud, S.C.; Romanovsky, V.E.; Hubbard, S.S. A distributed temperature profiling method for assessing spatial variability in ground temperatures in a discontinuous permafrost region of Alaska. Cryosphere 2019, 13, 2853-2867. [CrossRef]

104. Rohner, C.; Small, D.; Beutel, J.; Henke, D.; Lüthi, M.; Vieli, A. Multisensor validation of tidewater glacier flow fields derived from synthetic aperture radar (SAR) intensity tracking. Cryosphere 2019, 13, 2953-2975. [CrossRef]

105. Lendzioch, T.; Langhammer, J.; Jenicek, M. Estimating Snow Depth and Leaf Area Index Based on UAV Digital Photogrammetry. Sensors 2019, 19, 1027. [CrossRef] [PubMed]

106. Hendrickx, H.; Vivero, S.; De Cock, L.; De Wit, B.; De Maeyer, P.; Lambiel, C.; Delaloye, R.; Nyssen, J.; Frankl, A. The reproducibility of SfM algorithms to produce detailed Digital Surface Models: The example of PhotoScan applied to a high-alpine rock glacier. Remote. Sens. Lett. 2018, 10, 11-20. [CrossRef]

107. Lamsters, K.; Karušs, J.; Krievāns, M.; Ješkins, J. Application of Unmanned Aerial Vehicles for Glacier Research in the Arctic and Antarctic. In Proceedings of the 12th International Scientific and Practical Conference, Rezekne, Latvia, 20-22 June 2019.

108. Cook, J.M.; Tedstone, A.J.; Williamson, C.; McCutcheon, J.; Hodson, A.J.; Dayal, A.; Skiles, S.M.; Hofer, S.; Bryant, R.; McAree, O.; et al. Glacier algae accelerate melt rates on the south-western Greenland Ice Sheet. Crosph. Discuss. 2019. [CrossRef]

109. Cook, J.M.; Tedstone, A.J.; Williamson, C.; Mccutcheon, J.; Hodson, A.J.; Dayal, A.; Skiles, M.; Hofer, S.; Bryant, R.; Mcaree, O.; et al. Glacier Algae Accelerate Melt Rates on the South-Western Greenland Ice Sheet. Cryosphere 2020, 14, 309-330. [CrossRef]

110. Kanzow, T. Reports on Polar and Marine Research: The Expedition PS109 of the Research Vessel POLARSTERN to the Nordic Seas in 2017; Alfred-Wegener-Institut, Helmholtz-Zentrum für Polar- und Meeresforschung: Bremerhaven, Germany, 2018. [CrossRef]

111. Nolan, M.; Larsen, C.; Sturm, M. Mapping snow depth from manned aircraft on landscape scales at centimeter resolution using structure-from-motion photogrammetry. Cryosphere 2015, 9, 1445-1463. [CrossRef]

112. Mertes, J.R.; Gulley, J.D.; Benn, D.I.; Thompson, S.; Nicholson, L. Using structure-from-motion to create glacier DEMs and orthoimagery from historical terrestrial and oblique aerial imagery. Earth Surf. Process. Landforms 2017, 42, 2350-2364. [CrossRef]

113. Su, T.-C.; Chou, H.-T. Application of Multispectral Sensors Carried on Unmanned Aerial Vehicle (UAV) to Trophic State Mapping of Small Reservoirs: A Case Study of Tain-Pu Reservoir in Kinmen, Taiwan. Remote. Sens. 2015, 7, 10078-10097. [CrossRef]

114. DJI. Available online: https://www.dji.com/ (accessed on 14 March 2020).

115. DJI Developer. Available online: https:/developer.dji.com/mobile-sdk/documentation/introduction/ component-guide-airlink.html (accessed on 14 March 2020).

116. Tziavou, O.; Pytharouli, S.; Souter, J. Unmanned Aerial Vehicle (UAV) based mapping in engineering geological surveys: Considerations for optimum results. Eng. Geol. 2018, 232, 12-21. [CrossRef]

117. Yao, H.; Qin, R.; Chen, X. Unmanned Aerial Vehicle for Remote Sensing Applications-A Review. Remote Sens. 2019, 11, 1443. [CrossRef]

118. Nasrullah, A.R. Systematic Analysis of Unmanned Aerial Vehicle (UAV) Derived Product Quality. Master's Thesis, University of Twente, Twente, The Netherlands, February 2016. 
119. Bhardwaj, A.; Sam, L.; Bhardwaj, A.; Martín-Torres, F.J. LiDAR remote sensing of the cryosphere: Present applications and future prospects. Remote. Sens. Environ. 2016, 177, 125-143. [CrossRef]

120. Aisakestrel Data Sheet; Specim, Spectral Imaging Ltd.: Oulu, Finland, 2016. Available online: https: //www.specim.fi/downloads/AisaKESTREL-ver2-2016.pdf (accessed on 3 March 2020).

121. Micro-Hyperspec Imaging Sensors Data Sheet; Headwall Photonics, Inc.: Bolton, MA, USA, April 2018. Available online: https://cdn2.hubspot.net/hubfs/145999/June\%202018\%20Collateral/MicroHyperspec0418. pdf (accessed on 3 March 2020).

122. Jackisch, R.; Lorenz, S.; Zimmermann, R.; Möckel, R.; Gloaguen, R. Drone-Borne Hyperspectral Monitoring of Acid Mine Drainage : An Example from the Sokolov Lignite District. Remote Sens. 2018, 10, 385. [CrossRef]

123. Arroyo-Mora, J.P.; Kalacska, M.; Inamdar, D.; Soffer, R.J.; Lucanus, O.; Gorman, J.; Naprstek, T.; Schaaf, E.S.; Ifimov, G.; Elmer, K.; et al. Implementation of a UAV-Hyperspectral Pushbroom Imager for Ecological Monitoring. Drones 2019, 3, 12. [CrossRef]

124. Agisoft. Available online: https://www.agisoft.com/ (accessed on 14 March 2020).

125. Pix4D. Available online: https://www.pix4d.com/ (accessed on 14 March 2020).

126. MicMac. Available online: https://micmac.ensg.eu/index.php/Accueil (accessed on 14 March 2020).

127. Adobe. Available online: https://www.adobe.com/photoshop (accessed on 14 March 2020).

128. Eltner, A.; Kaiser, A.; Castillo, C.; Rock, G.; Neugirg, F.; Abellan, A. Image-based surface reconstruction in geomorphometry-Merits, limits and developments. Earth Surf. Dyn. 2016, 4, 359-389. [CrossRef]

129. Mölg, N.; Bolch, T. Structure-from-Motion Using Historical Aerial Images to Analyse Changes in Glacier Surface Elevation. Remote. Sens. 2017, 9, 1021. [CrossRef]

130. Mali, V.K.; Kuiry, S. Assessing the accuracy of high-resolution topographic data generated using freely available packages based on SfM-MVS approach. Measurement 2018, 124, 338-350. [CrossRef]

131. Duffy, J.; Cunliffe, A.M.; Debell, L.; Sandbrook, C.; Wich, S.A.; Shutler, J.D.; Myers-Smith, I.H.; Varela, M.R.; Anderson, K. Location, location, location: Considerations when using lightweight drones in challenging environments. Remote. Sens. Ecol. Conserv. 2017, 4, 7-19. [CrossRef]

132. UAV Coach. Available online: https://uavcoach.com/ (accessed on 14 March 2020).

133. Global Drone Regulations Database. Available online: https://www.droneregulations.info (accessed on 14 March 2020).

134. ICAO UAS Toolkit. Available online: https://www.icao.int/safety/UA/UASToolkit/Pages/State-Regulations. aspx (accessed on 14 March 2020).

135. Stöcker, C.; Bennett, R.; Nex, F.; Gerke, M.; Zevenbergen, J. Review of the Current State of UAV Regulations. Remote Sens. 2017, 9, 459. [CrossRef]

136. Crowe, W.; Davis, K.D.; la Cour-Harbo, A.; Vihma, T.; Lesenkov, S.; Eppi, R.; Weatherhead, E.C.; Liu, P.; Raustein, M.; Abrahamsson, M.; et al. Enabling Science Use of Unmanned Aircraft Systems for Arctic Environmental Monitoring, 6th ed.; Arctic Monitoring and Asessment Programme (AMAP): Oslo, Norway, 2012; p. 30.

137. Otsuka, H.; Sasaki, D.; Nagatani, K. Reduction of the head-up pitching moment of small quad-rotor unmanned aerial vehicles in uniform flow. Int. J. Micro Air Veh. 2017, 10, 85-105. [CrossRef]

138. Gaffey, C.B.; Buyantuev, A.; Lapenis, A. A Comparison of White Spruce Phenology Detected from Ground, Satellite, and Drone's Eve View. In Proceedings of the American Association of Geographers Annual Meeting, Washington, DC, USA, 3-7 April 2019.

139. Chudley, T.R.; Christoffersen, P.; Doyle, S.H.; Abellan, A.; Snooke, N. High-accuracy UAV photogrammetry of ice sheet dynamics with no ground control. Cryosphere 2019, 13, 955-968. [CrossRef]

140. James, M.R.; Robson, S. Mitigating systematic error in topographic models derived from UAV and ground-based image networks. Earth Surf. Process. Landforms 2014, 39, 1413-1420. [CrossRef]

141. DeWitt, B.A.; Wolf, P.R. Elements of Photogrammetry (with Applications in GIS), 3rd ed.; McGraw-Hill Higher Education: New York, NY, USA, 2000.

142. Tahar, K.N. An Evaluation on Different Number of Ground Control Points in Unmanned Aerial Vehicle Photogrammetric Block. ISPRS Int. Arch. Photogramm. Remote. Sens. Spat. Inf. Sci. 2013, 40, 93-98. [CrossRef]

143. Tonkin, T.; Midgley, N. Ground-Control Networks for Image Based Surface Reconstruction: An Investigation of Optimum Survey Designs Using UAV Derived Imagery and Structure-from-Motion Photogrammetry. Remote. Sens. 2016, 8, 786. [CrossRef] 
144. Sanz-Ablanedo, E.; Chandler, J.; Rodriguez-Perez, J.R.; Ordóñez, C. Accuracy of Unmanned Aerial Vehicle (UAV) and SfM Photogrammetry Survey as a Function of the Number and Location of Ground Control Points Used. Remote. Sens. 2018, 10, 1606. [CrossRef]

145. Campbell, J.B. Introduction to remote sensing. Geocarto Int. 1987, 2, 64. [CrossRef]

146. Storvold, R.; Sweatte, C.; Ruel, P.; Wuennenberg, M.; Tarr, K.; Raustein, M.; Hillesøy, T.; Lundgren, T.; Sumich, M. Arctic Science RPAS Operator's Handbook; Arctic Monitoring and Assessment Programme (AMAP): Olso, Norway, 2015.

147. UNOLS 2018 SCOAR Meeting-Appendix VIII: UAF UAV Operations. Available online: https://www.unols. org/document/2018-scoar-meeting----appendix-viii-uaf-uav-operations (accessed on 14 March 2020).

148. US ATCM. Considerations for the Use of Unmanned Aircraft Systems (UAS) for Research, Monitoring, and Observation in Antarctica; ATCM XXXVII; US ATCM: Brasilia, Brazil, 2014.

149. Council of Managers of National Antarctic Programs (COMNAP). Antarctica in International Law; Version 31; Bloomsbury Academic: New York, NY, USA, 2015.

(C) 2020 by the authors. Licensee MDPI, Basel, Switzerland. This article is an open access article distributed under the terms and conditions of the Creative Commons Attribution (CC BY) license (http://creativecommons.org/licenses/by/4.0/). 